\title{
Las terrazas fluviales del río Cares: aportaciones sedimentológicas y cronológicas (Picos de Europa, Asturias) $)^{1}$
}

\section{The fluvial terraces of the Cares river: sedimentological and chronological contributions (Picos de Europa, Asturias)}

Jesús Ruiz Fernández y Miguel Ángel Poblete Piedrabuena*

\section{INTRODUCCIÓN}

Los ríos de la vertiente Norte de la Cordillera Cantábrica son cortos en comparación con otros sistemas fluviales de la Península Ibérica, pero en cambio tienen un gran caudal merced a las importantes precipitaciones que reciben sus cuencas, fuertes pendientes y una cabecera elevada, por lo que han sido capaces de labrar angostos desfiladeros. Los estudios geomorfológicos efectuados al respecto, junto con otras disciplinas, han precisado diversos niveles de terraza en los ríos Aboño (1), Aránzazu (3), Besaya (6), Eo (10), Masma (1), Nalón (11), Nora (3), Oiartzun (7), Oro (6), Pas (6), Porcía (5), Sella (12) y Trubia (7) (cuadro 1).

\footnotetext{
${ }^{1}$ Este trabajo se ha realizado con el apoyo financiero del proyecto «El paisaje natural de los Picos de Europa: gestión y desarrollo sostenible» (ref.: UNOV-07-MB-208 y UNOV-08-RENOV208). Los autores agradecen a los Drs. José María García-Ruiz y Enrique Serrano Cañadas, así como a los evaluadores anónimos del trabajo, sus comentarios y sugerencias, que han contribuido a mejorar la calidad del manuscrito original.

* Departamento de Geografía, Universidad de Oviedo. España (e-mail: ruizjesus@uniovi.es y mpoblete@uniovi.es, respectivamente).
} 
CuAdro 1

NIVELES DE TERRAZA IDENTIFICADOS EN LOS RÍOS CANTÁBRICOS

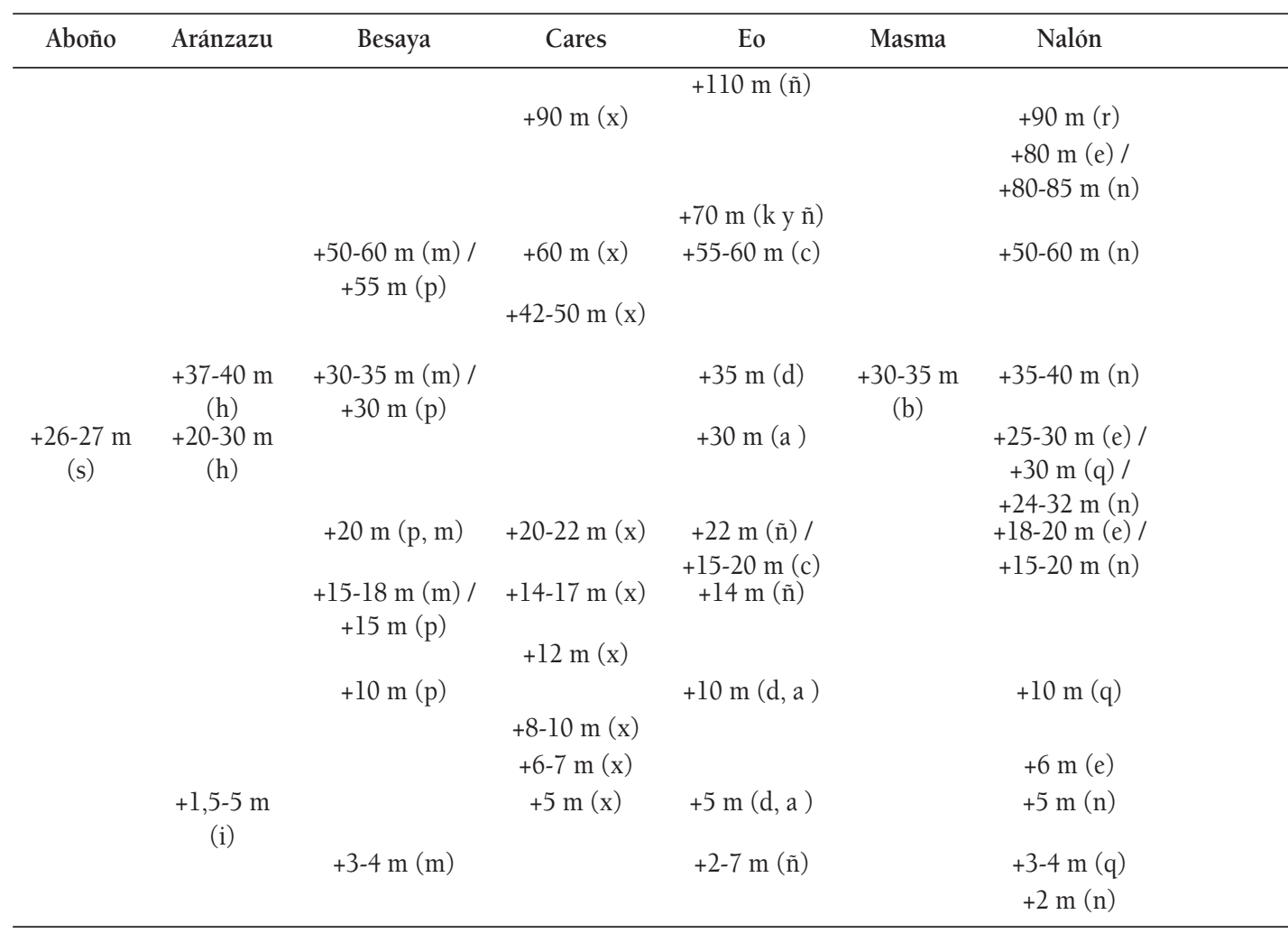

Asensio y Nonn (1964a) (a), Asensio y Nonn (1964b) (b), Asensio (1967) (c), Asensio (1970) (d), Mary (1983) (e), Gómez (1983) (f), Rodríguez (1983) (g), Ugarte, González y Alonso (1984) (h), Ugarte, LópezAzcona y González (1986) (i), Navarro y Leyva (1986) (j), Asensio y Lombardero (1987) (k), Edeso y

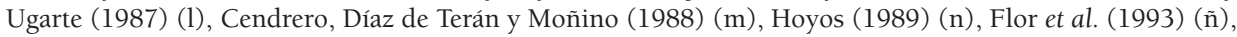

También se han aportado algunas propuestas cronológicas, destacando en este sentido los trabajos de Asensio y Nonn (1964a y 1964b), que atribuyen las terrazas $+5,+12$ y $+15 \mathrm{~m}$ del río Oro al interglaciar Riss-Würm, mientras que los niveles $+30 \mathrm{~m}$ del Eo, $+30-35 \mathrm{~m}$ del Masma y $+40 \mathrm{~m}$ del Oro los adscriben al interglaciar Mindel-Riss. Según Gómez (1983) el nivel +45 m del río Porcía correspondería igualmente al interglaciar Mindel-Riss, la T +25 m fosilizada por derrubios de ladera al interglaciar Riss-Würm y la $\mathrm{T}+12 \mathrm{~m}$ al würmiense. Asensio y Lombardero (1987) asignan la terraza $+70 \mathrm{~m}$ del Eo al 


\begin{tabular}{|c|c|c|c|c|c|c|}
\hline Nora & Oiartzun & Oro & Pas & Porcía & Sella & Trubia \\
\hline & & & & & $+110 \mathrm{~m}(\mathrm{w})$ & $+115 \mathrm{~m}(\mathrm{u})$ \\
\hline & & & & $+75-80 \mathrm{~m}(\mathrm{w})$ & +80 m (u) & \\
\hline \multirow[t]{3}{*}{ +55 $\mathrm{m} \mathrm{(o)}$} & & $+55 \mathrm{~m}(\mathrm{~b})$ & $+60 \mathrm{~m}(\mathrm{p})$ & & $+60-65 \mathrm{~m}(\mathrm{w}) /$ & $+50-60 \mathrm{~m}(\mathrm{u})$ \\
\hline & & $+40 \mathrm{~m}(\mathrm{~b})$ & & $+45 \mathrm{~m}(\mathrm{f})$ & $+40-50 \mathrm{~m}(\mathrm{w}) /$ & $+40 \mathrm{~m}(\mathrm{u})$ \\
\hline & $+30-32 \mathrm{~m}(\mathrm{v})$ & & $+35 \mathrm{~m}(\mathrm{p})$ & & & \\
\hline \multirow[t]{2}{*}{$+25 \mathrm{~m} \mathrm{(o)}$} & & & & $+25 \mathrm{~m}(\mathrm{f})$ & $+27-30 \mathrm{~m}(\mathrm{w})$ & +30 m (u) \\
\hline & $+20-22 \mathrm{~m} \mathrm{(l)} \mathrm{/}$ & $+25 \mathrm{~m} \mathrm{(b)}$ & $+20 \mathrm{~m}(\mathrm{p})$ & & $+20 \mathrm{~m} \mathrm{(w)}$ & \\
\hline \multirow[t]{8}{*}{$+15 \mathrm{~m}(\mathrm{~g})$} & $\begin{array}{l}+18-22 \mathrm{~m}(\mathrm{v}) \\
+15-16 \mathrm{~m}(\mathrm{l})\end{array}$ & $+15 \mathrm{~m}(\mathrm{~b})$ & $+15 \mathrm{~m}(\mathrm{p})$ & & +17 m (w) & \\
\hline & & $+12 \mathrm{~m}(\mathrm{~b})$ & & $+12 \mathrm{~m}(\mathrm{f})$ & $+12 \mathrm{~m}(\mathrm{w})$ & \\
\hline & $+10-12 \mathrm{~m}(\mathrm{l}, \mathrm{v})$ & & $+10 \mathrm{~m}(\mathrm{p})$ & $+10 \mathrm{~m}(\mathrm{f})$ & +10 m (w) & \\
\hline & & & & & +8 m (w) & \\
\hline & & & & & +6 m (w) & $+5-6 \mathrm{~m} \mathrm{(u)}$ \\
\hline & $+4-5 \mathrm{~m}(\mathrm{l})$ & $+5 \mathrm{~m}(\mathrm{~b})$ & & & +4 m (w) & \\
\hline & $+3-4 \mathrm{~m}(\mathrm{v})$ & & & & & $+2-3 \mathrm{~m}(\mathrm{u})$ \\
\hline & $+0-2 \mathrm{~m}(\mathrm{v})$ & & $+2,5 \mathrm{~m}(\mathrm{p})$ & $+1-2 \mathrm{~m}(\mathrm{f})$ & & \\
\hline
\end{tabular}

Noval (1995) (o), González et al. (1996) (p), Jiménez (1999) (q), Rodríguez (2001) (r), Estrada y Jordá (2003) (s), Requejo y Jiménez (2003) (t), Fernández et al. (2005) (u), Edeso (2006) (v), Fernández-Irigoyen y Ruiz-Fernández (2008) (w), contribuciones de este artículo (x).

Günz-Mindel, mientras que Cendrero, Díaz de Terán y Moñino (1988) sitúan la formación de la T +20 m del río Saja-Besaya en el Pleistoceno superior, señalando además que existe una correspondencia entre los niveles marinos y las terrazas fluviales de dicho curso para las alturas actuales sobre el cauce de $+3-4,+15-18,+30-35$ y $+50-60 \mathrm{~m}$.

Según Hoyos (1989) las terrazas $+80-85$ y +50-60 m del río Nalón pertenecerían al Pleistoceno inferior, el nivel $+35-40 \mathrm{~m}$ al Pleistoceno inferior/medio, los niveles +24-32 y +15-20 al Pleistoceno superior y, por último, los niveles 
$+5 \mathrm{y}+2 \mathrm{~m}$ al Pleistoceno superior y al Holoceno respectivamente. En el valle del Nansa Frochoso (1990) identifica 3 fases torrenciales, correlacionando la segunda y la tercera con los niveles marinos bajos estudiados por Mary (1983). Concretamente manifiesta que la segunda fase torrencial está asociada con el nivel marino de 35-40 m, atribuyéndola al Pleistoceno medio, y la tercera enlaza con el nivel de 5-6 m, por lo que sitúa su edad a inicios del Pleistoceno superior (interglaciar Riss-Würm).

Edeso (2006) en su estudio sobre las terrazas fluviales del río Oiartzun considera que los niveles $+3-5,+10-12$ y $+18-22$ m pertenecerían al Pleistoceno superior y/o medio, mientras que la $\mathrm{T}+0-2 \mathrm{~m}$ sería holocena. Según dicho autor la deposición de la $\mathrm{T}+18-22$ m podría corresponder al Riss o los inicios del Würm, ya que se produjo en condiciones de rexistasia, con depósitos coluviales fosilizando y mezclándose con las acumulaciones fluviales; mientras que el nivel $+10-12 \mathrm{~m}$ lo vincula al Würm y la $\mathrm{T}+3-5 \mathrm{~m}$ a otro enfriamiento climático fechado a partir de 14.700 años BP (Tardiglaciar).

Por último, González et al. (1996) proponen un modelo cronológico para los ríos Pas y Besaya basado en dataciones radiocarbónicas e indicios arqueológicos. Según estos autores las edades serían más recientes, en concreto, la $\mathrm{T}_{6}$ de dichos ríos (+55 m) tendría una edad superior a 90.000-120.000 años BP, la $\mathrm{T}_{5}(+44 \mathrm{~m}$ en el Pas y $+30 \mathrm{~m}$ en el Besaya) se situaría entre 90.000-120.000 y 47.270 años BP, la $\mathrm{T}_{4}(+20 \mathrm{~m})$ en $5.490 \pm 90$ años $\mathrm{BP}$, la $\mathrm{T}_{3}(+15 \mathrm{~m})$ en $4.900 \pm 100$ años BP, la $\mathrm{T}_{2}(+10 \mathrm{~m})$ cerca de 2.800 años $\mathrm{BP}$ y, finalmente, la $\mathrm{T}_{1}$ $(+2,5 \mathrm{~m})$ apenas contaría con unos 200 años de antigüedad. Salvo este último trabajo, el resto de cronologías están basadas en correlaciones con otros depósitos, en procedimientos arqueológicos o en interferencias entre los depósitos fluviales y otras formas de modelado, es decir, en criterios relativos, pero no en dataciones absolutas. En definitiva, pese a las aportaciones previas existe todavía un gran desconocimiento en lo concerniente a las edades de las terrazas fluviales de los ríos cantábricos, por lo que es necesario realizar nuevas investigaciones tendentes a paliar este vacío, así como a profundizar en los factores que controlan la evolución de dichos sistemas fluviales.

El Cares es sin duda uno de los ríos prototipo de la vertiente Norte de la Cordillera Cantábrica, puesto que cumple con todas las características anteriormente reseñadas. Ha sido capaz de labrar uno de los desfiladeros más conocidos de España, que hace de límite entre el Macizo Central de los Picos de Europa y el Occidental y cuenta con grandes desniveles, cercanos incluso a los $2.000 \mathrm{~m}$. No obstante también ha sido capaz de depositar abundantes materia- 
les, siendo la depresión de Arenas de Cabrales el primer enclave en el que el río ha modelado un sistema de terrazas bien desarrollado tras atravesar los Picos de Europa; de ahí que seleccionáramos dicho sector para realizar el presente estudio.

Los objetivos del trabajo son: 1) establecer los niveles de terraza del río Cares en Arenas de Cabrales; 2) efectuar una cartografía geomorfológica detallada de la zona de estudio; 3) profundizar en el comportamiento hidrodinámico del Cares y sus afluentes a través del análisis sedimentológico de la fracción fina y gruesa de los depósitos fluviales; 4) establecer la cronología de varios niveles de terraza mediante dataciones de $\mathrm{C}^{14}$ en los propios sedimentos fluviales o en otras formas de modelado que los fosilizan (abanicos torrenciales y derrubios estratificados); 5) situar la evolución hidrodinámica y cronológica del río Cares en el contexto de la Vertiente Cantábrica.

\section{EL ÁREA DE ESTUDIO Y SU ORGANIZACIÓN MORFOESTRUCTURAL}

El área de estudio seleccionada se localiza en la depresión de Arenas de Cabrales, donde confluyen el río Cares y sus tributarios Casaño y Ribeles. La depresión queda delimitada al Norte y al Oeste por los interfluvios de la vertiente meridional de la Sierra del Cuera, que constituye la mayor y más elevada de las sierras litorales asturianas, pues se prolonga paralela a la costa a lo largo de unos $30 \mathrm{~km}$ y alcanza $1.315 \mathrm{~m}$ de altitud en la Cabeza Turbina. Hacia el Este limita con la Sierra de Juan Robre y Jana, dispuesta en dirección ENEOSO a lo largo de unos $8 \mathrm{~km}$ de longitud, justo entre las localidades de Arenas de Cabrales y Trescares, y cuya cota más alta es el Jorcau del Cuernu, con 976 m. Finalmente, hacia mediodía queda cerrada por las sierras de Portudera y Dobros, es decir, por las estribaciones más septentrionales de los Picos de Europa (figura 1).

Desde el punto de vista geológico la depresión de Arenas de Cabrales se halla en el área de contacto de dos grandes unidades estructurales: la Región de Mantos y el Dominio de Picos de Europa. La primera está integrada por una sucesión de láminas alóctonas imbricadas que han sufrido desplazamientos horizontales de longitud variable. Estas estructuras de despegue, definidas por el afloramiento de materiales del Cámbrico, el Ordovícico, el Devónico superior y el Carbonífero, fueron plegadas con posterioridad a su emplazamiento y se hallan rotas por fracturas transversales (Julivert, 1967 y 1983; Bahamonde y Colmenero, 1993; Navarro, Leyva y Villa, 1986). Por su parte, el Dominio de Picos de Europa está formado por la sucesión de diversas escamas cabalgantes 
FIGURA 1

LOCALIZACIÓN DE LA ZONA DE ESTUDIO

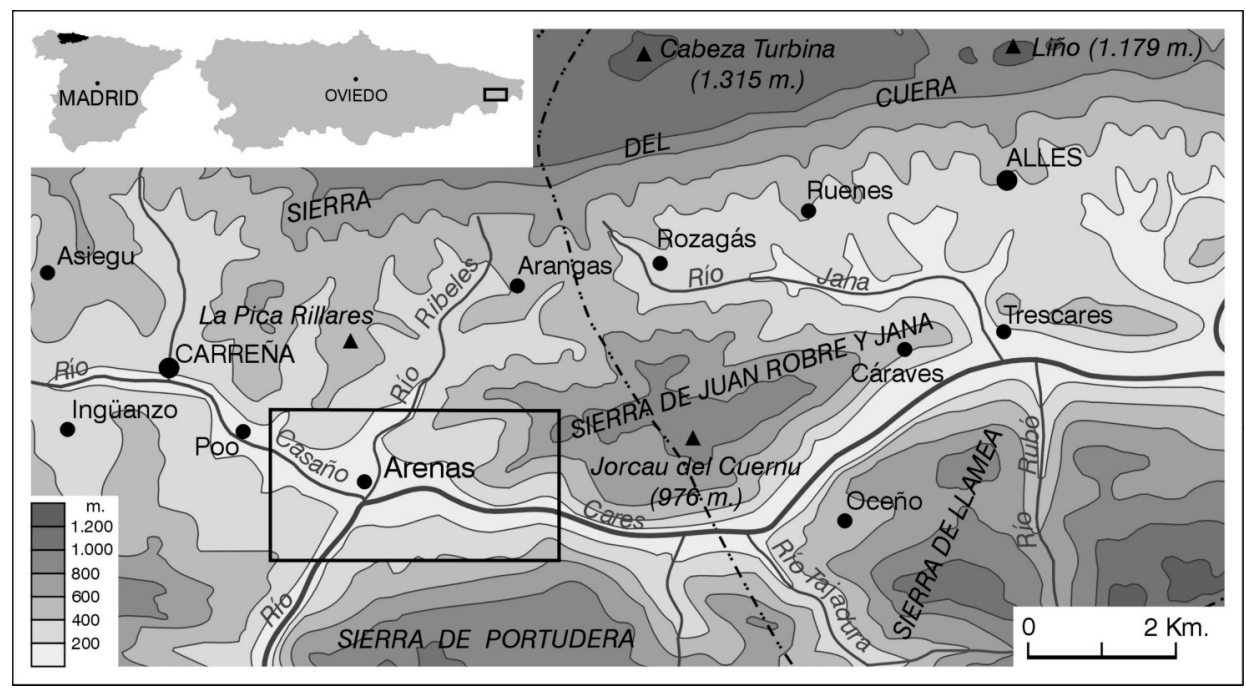

imbricadas y compuestas básicamente por calizas carboníferas (Marquínez, 1978 y 1989; Farias, 1982). Dichas escamas, de vergencia Sur y rumbo aproximado E-O, han sido afectadas posteriormente por pliegues y por una red de fallas en desgarre dextrales, de rumbo ONO-ESE y con los labios occidentales elevados (Marquínez, 1978). Esta región estructural se halla cabalgada por la prolongación NE de la Región de Mantos y a su vez monta por el Sur a las series devónicas y carboníferas de la Región del Pisuerga-Carrión.

La cabecera del río Cares, situada en la cuenca de Valdeón, está excavada fundamentalmente sobre areniscas, lutitas, calizas y conglomerados devónicos y carboníferos. No obstante, al atravesar los Picos de Europa, que están integrados esencialmente por calizas, la mayor parte de los materiales transportados por este río al llegar a la depresión de Arenas de Cabrales son de naturaleza calcárea. En cambio, la cabecera del río Casaño, ubicada en el sector nororiental del Macizo del Cornión, está labrada sobre calizas carboníferas aunque los aportes laterales que recibe son principalmente de cuarcitas, areniscas y pizarras del Ordovícico y del Carbonífero, predominando en consecuencia en sus depósitos los materiales silíceos y especialmente las cuarcitas de la Fm. Barrios. Finalmente, la mayor parte de la cuenca del Ri- 
beles está modelada sobre cuarcitas, por lo que arrastra casi en exclusiva dicha litología.

Por lo que respecta al roquedo que integra la depresión de Arenas, es de naturaleza tanto silícea como carbonatada, destacando en primer lugar las cuarcitas ordovícicas de la Fm. Barrios, formadas por hiladas de gran espesor que cabalgan al Norte de Arenas sobre las calizas de Picos de Europa (Westfaliense B-Cantabriense). Esta última formación, que constituye la litología que mayor extensión ocupa dentro del ámbito de estudio, enmarcando el sistema de terrazas por el Norte, el Este y parcialmente por el Sur, está constituida por dos miembros: uno inferior de calizas claras tableadas alternando con pizarras y otro superior de calizas masivas de tonos grises o rosados (Marquínez, 1978; Farias, 1982). Finalmente, hacia el Sur y el Oeste de Arenas de Cabrales, así como en la propia localidad, yace una sucesión turbidítica compuesta por lutitas y areniscas con intercalaciones carbonatadas y niveles de carbón de escasa importancia, denominada Fm. Cavandi. Tal sucesión, perteneciente a la cuenca estefaniense de Gamonedo-Cabrales-Panes, se apoya discordantemente sobre los materiales más antiguos del Carbonífero (Navarro, Leyva y Villa, 1986).

\section{Metodología}

Mediante trabajo de campo y fotointerpretación se procedió a la localización e identificación de los diversos niveles de terraza del río Cares y sus tributarios, así como de otras formas de modelado, a fin de elaborar un esquema geomorfológico de la depresión de Arenas de Cabrales (figura 2).

En cuanto a los depósitos aluviales conviene aclarar que los análisis sedimentológicos, fundamentales para esclarecer en parte los mecanismos de deposición, las variaciones en el comportamiento hidrodinámico y las condiciones ambientales imperantes durante su génesis, han sido efectuados en todos los niveles donde hemos encontrado cortes adecuados, prescindiendo de los recuentos en superficie que pudieran desvirtuar los resultados.

Para los análisis granulométricos de la fracción gruesa y fina seguimos la metodología establecida por Cailleux y Tricart (1965), consistente en el primer caso en los recuentos granulométricos de cantos y bloques, la elaboración de los espectros litológicos y los análisis morfométricos de lotes de cantos de idéntica naturaleza (la predominante en cada depósito analizado), y de eje mayor (L) comprendidos entre 4 y $6 \mathrm{~cm}$, a fin de conocer los índices de desgaste, aplanamiento y disimetría. 
La fracción fina de las muestras se ha analizado en el laboratorio mediante la eliminación de la materia orgánica y el tamizado en seco, obteniendo a partir de dicho proceso el cálculo de los siguientes parámetros e índices estadísticos: mediana, media empírica, índice de Trask, desviación típica, coeficiente de disimetría (Skewness) y de acuidad (Kurtosis) (Folk y Ward, 1957; Folk, 1980). Estos datos se completan con el estudio de las facies de las curvas acumulativas.

Por último se han efectuado dataciones de $\mathrm{C}^{14}$ en la $\mathrm{T}+8-10 \mathrm{~m}$ y en la $\mathrm{T}+20-22 \mathrm{~m}$ de Arenas de Cabrales, en los derrubios estratificados que fosilizan un retazo de abanico torrencial colgado a $+20-22 \mathrm{~m}$ sobre el río Cares en Praón (entre Poncebos y Arenas de Cabrales), así como en un cono torrencial que fosiliza la $\mathrm{T}+10 \mathrm{~m}$ del río Sella en las cercanías de Las Rozas. Las muestras fueron datadas en los laboratorios polacos Poznan Radiocarbon Laboratory (Foundation of the Adam Mickiewicz University) y Gliwice Absolute Dating Methods Centre (GADAM Centre, Silesian University of Tehnology). Las edades $\mathrm{C}^{14}$ obtenidas han sido calibradas con la curva Intcal04 (Reimer et al. 2004) y el programa OxCal v3.10 (Bronk Ramsey, 2005) (cuadro 2).

CUADRO 2

DESCRIPCIÓN Y RESULTADOS DE LAS DATACIONES DE C ${ }^{14}$ EFECTUADAS EN LAS TERRAZAS +8-10 M Y +20-22 M DE MORADIELLOS Y EL CORNEYAL (ARENAS DE CABRALES), EN LOS DERRUBIOS ESTRATIFICADOS DE PRAÓN (ARROYO AFLUENTE DEL CARES), Y EN EL CONO DE DEYECCIÓN DE LAS ROZAS (RÍO SELLA)

\begin{tabular}{lll}
\hline Muestra & Referencia & Método \\
\hline $\begin{array}{l}\text { M1. Terraza + 8-10 m (Moradiellos, Arenas } \\
\text { de Cabrales) }\end{array}$ & Poz-27626 & AMS \\
$\begin{array}{l}\text { M2. Terraza + 20-22 m } \\
\text { (El Corneyal, Arenas de Cabrales) }\end{array}$ & Poz-24483 & AMS \\
$\begin{array}{l}\text { M3. Derrubios estratificados de Praón } \\
\text { M4. Cono torrencial de Las Rozas }\end{array}$ & Gd-12912 & $\begin{array}{l}C^{14} \text { convencional } \\
(\text { GPC) }\end{array}$ \\
\hline
\end{tabular}




\section{RESULTADOS}

\section{Las terrazas fluviales: características morfológicas y sedimentarias}

En Arenas de Cabrales, el río Cares y sus afluentes el Casaño y el Ribeles han depositado a lo largo del Cuaternario un sistema de terrazas fluviales integrado al menos por 9 niveles, con alturas de $+90 \mathrm{~m},+60 \mathrm{~m},+42-50 \mathrm{~m},+20-22$ $\mathrm{m},+14-17 \mathrm{~m},+12 \mathrm{~m},+8-10 \mathrm{~m},+6-7 \mathrm{~m} \mathrm{y}+5 \mathrm{~m}$ sobre el nivel actual del cauce (figuras 2 y 3 ).

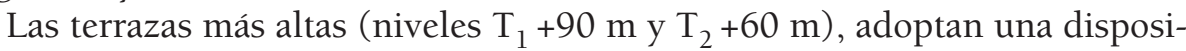
ción escalonada y colgada, aflorando en ambas el sustrato geológico. Tienen además depósitos aluviales de apenas unos metros de espesor, con estructuras masivas, sin gradaciones y con texturas de soporte matricial. Por el contrario, las terrazas medias y bajas están encajadas o embutidas y, en general, tienen mayor espesor. No obstante, constan también de una estructura masiva y caótica aunque con texturas fundamentalmente de soporte clástico.

Nivel de terraza fluvial $+90 m\left(T_{1}, 225\right.$ m s.n.m. $)$

Este nivel está compuesto por un único resto localizado al Sureste de Arenas de Cabrales, concretamente en las inmediaciones del cementerio de Pandu (margen derecha del río Cares). Se trata de una terraza de pequeñas dimensiones y escaso espesor (entre 1 y $2 \mathrm{~m}$ ), pues ha sido desmantelada en gran parte. Su planta es elíptica y se halla exenta de la ladera al estar flanqueada por dos surcos de arroyada que la individualizan. Su estructura se aprecia en un corte superficial que aunque no presenta las mejores condiciones para el análisis de la fracción gruesa sí permite comprobar su origen fluvial, puesto

$\begin{array}{lll}\text { Materiales datados } & \text { Edad C } & \text { Edad calibrada } \\ \text { Carbón vegetal } & 37.300 \pm 800 \mathrm{BP} & 39.101-35.830 \text { calBP }(95,4 \%) \\ \text { Carbón vegetal } & >48.000 \mathrm{BP} & \\ \text { Restos de caracoles } & 9.450 \pm 80 \mathrm{BP} & 11.100-10.450 \text { calBP }(95,4 \%) \\ \text { Sedimento orgánico } & 2.625 \pm 55 \mathrm{BP} & 2.860-2.690 \text { calBP }(81,6 \%)\end{array}$


FIGURA 2

ESQUEMA GEOMORFOLÓGICO DEL SISTEMA DE TERRAZAS FLUVIALES DE ARENAS DE CABRALES
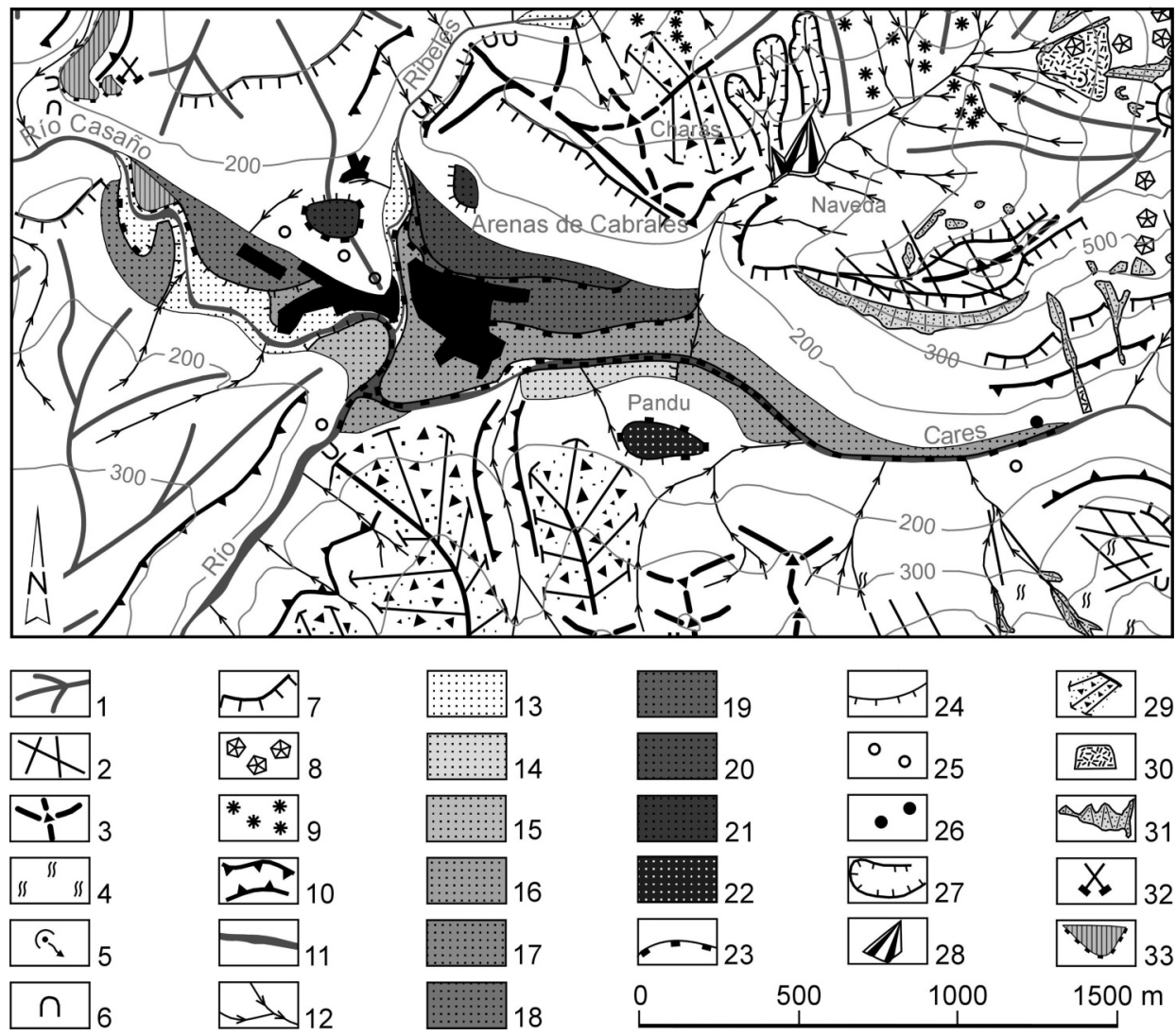

1.- Interfluvios. 2.- Fracturas. 3.- Relieves calcáreos residuales. 4.- Campo de lapiaz. 5.- Surgencia. 6.Cueva, abrigo rocoso. 7.- Escarpe rocoso. 8.- Porrones calcáreos. 9.- Tors cuarcíticos. 10.- Garganta, cauce encajado. 11.- Río. 12.- Surco de arroyada. 13.- Fondo de valle aluvial. 14. Terraza +5 m. 15.- Terraza +6-7 m. 16.- Terraza +8-10 m. 17.-Terraza +12 m. 18.- Terraza +14-17 m. 19.- Terraza +20-22 m. 20.- Terraza +42-50 m. 21.- Terraza +60 m. 22.- Terraza +90 m. 23.- Borde abrupto de terraza fluvial. 24.- Borde difuminado de terraza fluvial. 25.- Depósito fluvial sin cementar. 26.- Depósito fluvial cementado. 27.- Cabecera torrencial. 28.- Cono de deyección. 29.- Vertiente regularizada por acumulación. 30.- Derrubios estratificados cementados. 31.- Taludes y conos de derrubios. 32. Mina inactiva. 33.- Escombrera. 


\section{FIGURA 3}

VISTA PARCIAL DEL SISTEMA DE TERRAZAS DESDE PANDU ( $+90 \mathrm{M})$

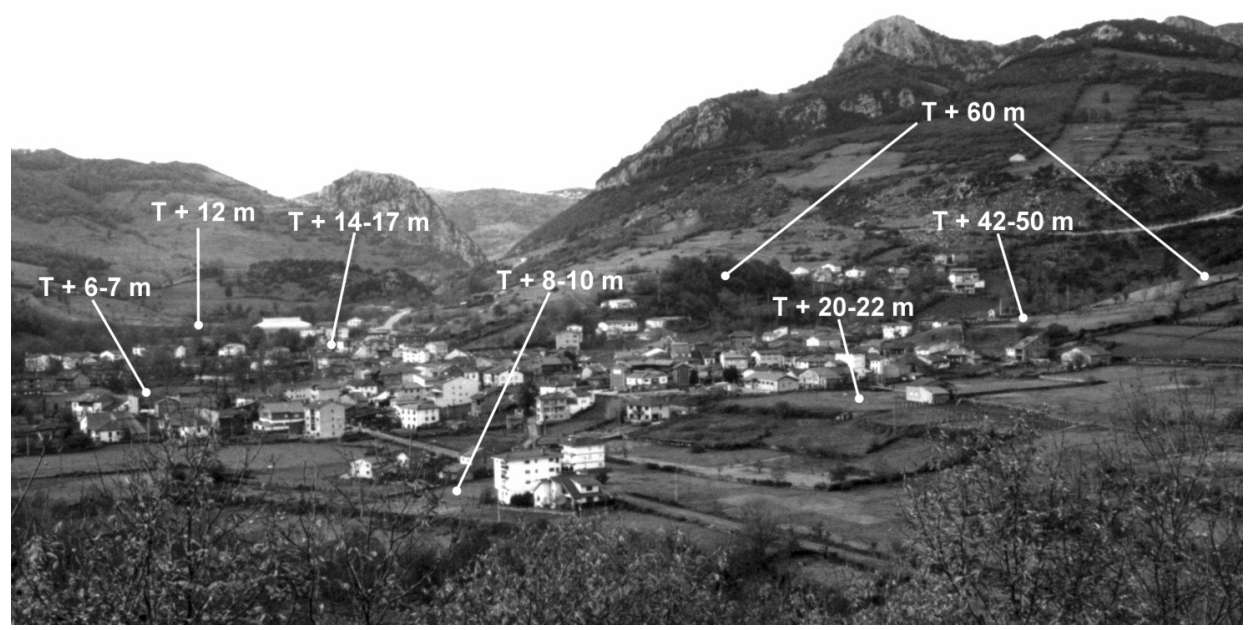

que se aprecian gravas calcáreas y gravas y cantos de cuarcita muy rodados y envueltos en una matriz fina. Por otro lado, en las vertientes que descienden de la terraza y especialmente en los cortes de la pista que da acceso al cementerio, se observa un depósito de ladera integrado por bloques y cantos angulosos empastados en una matriz fina de textura arenosa; en el que incluso hay gravas y pequeños cantos derrubiados de la terraza, lo cual ratifica el origen antiguo de este nivel.

La matriz fina de los aluviones tiene una tonalidad amarilla marrón (10 YR 6/6), con más fracción arenosa (55,5\%) que limo-arcillosa (44,5\%). El reparto de las arenas se caracteriza por el escaso contenido de partículas gruesas $(10,8 \%)$ y el predominio de los tamaños medio $(23,77 \%)$ y fino $(20,93 \%)$. La media y la mediana alcanzan valores moderados, esto es, dentro de la fracción de arenas medias $\left(\mathrm{M}_{\mathrm{z}}=305 \mu\right.$ y $\left.\mathrm{Md}=276 \mu\right)$; mientras que los índices granulométricos muestran un depósito de moderadamente bien clasificado $\left(\mathrm{S}_{0}=1,57 \Phi\right)$ a moderadamente clasificado $\left(\sigma_{\Phi}=1,1 \Phi\right)$, con una curva acumulativa de arranque logarítmico y marcada inflexión a partir de 0,8 mm; ligeramente disimétrica por el predominio de partículas finas $\left(\mathrm{SK}_{\mathrm{I}}=0,24 \Phi\right)$ y achatada, es decir, platicúrtica $\left(\mathrm{K}_{\mathrm{G}}=0,46 \Phi\right)$ (figura 4 ). 
FigURA 4

CURVAS GRANULOMÉTRICAS ACUMULATIVAS DE LA FRACCIÓN ARENOSA

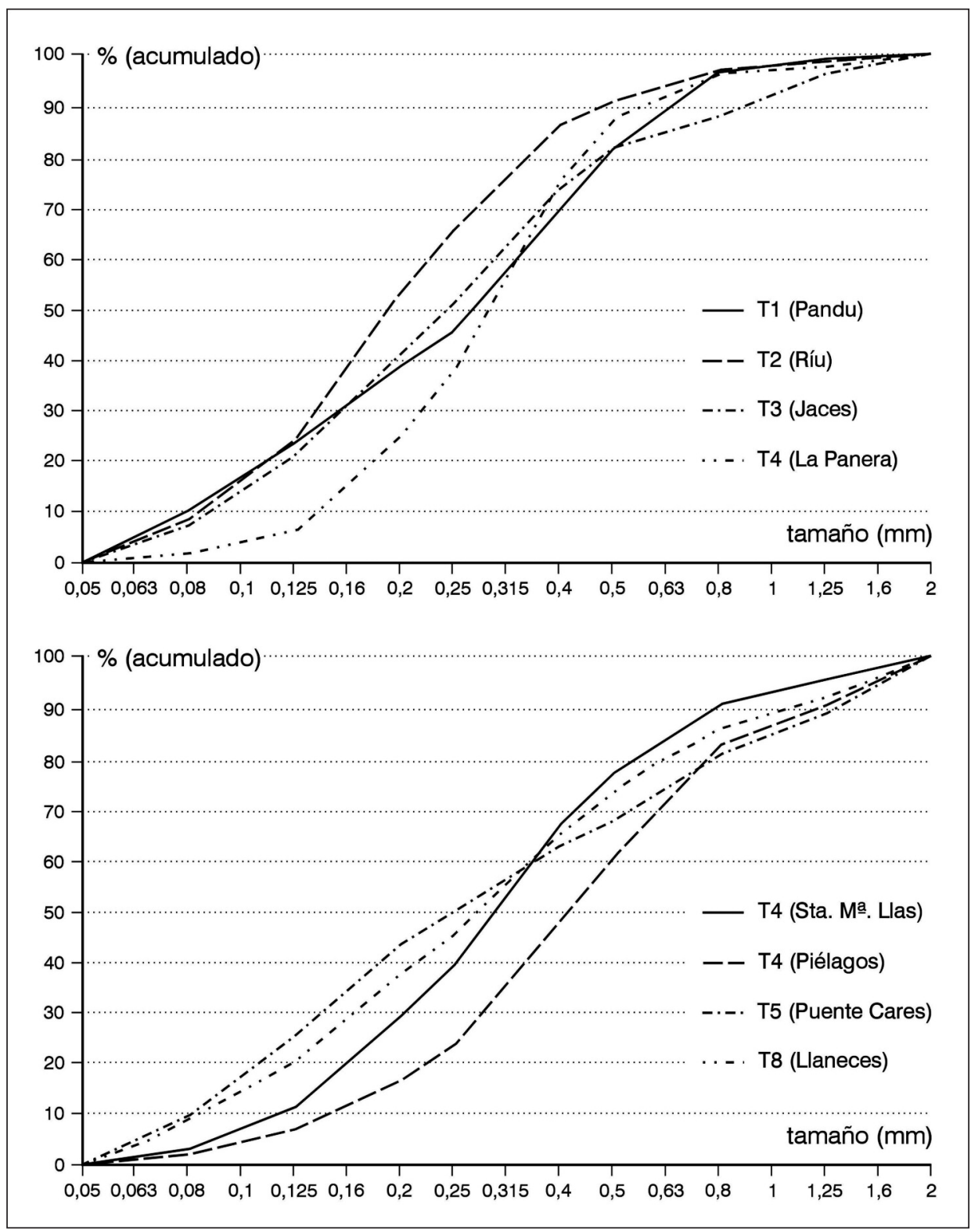

Estudios Geográficos, Vol. LXXII, 270, pp. 173-202, enero-junio 2011

ISSN: 0014-1496, eISSN: 1988-8546, doi: 10.3989/estgeogr.201108 
Nivel de terraza fluvial $+60 m\left(T_{2}, 195\right.$ m s.n.m. $)$

Este nivel está integrado por dos pequeños restos. El primero se sitúa en la margen derecha del río Ribeles, levantándose sobre su borde NE el barrio de Ríu (Arenas). La planta de la terraza es aproximadamente circular, con un perfil alomado y unos bordes bastante difuminados, a excepción de su extremo Este. Tiene un espesor visible de unos $5 \mathrm{~m}$ y está exenta de la ladera, pues tanto hacia el Oeste como hacia el Este se halla incidida por dos pequeños surcos de arroyada (figura 2). La estructura se percibe bien en un corte de escasa profundidad existente en una pista, así como en el escarpe oriental. Los materiales groseros son fundamentalmente de naturaleza silícea, y los análisis granulométricos revelan que la matriz fina, de tonalidad marrón pálido (10 YR 7/4), es casi tan arenosa (50,43\%) como limo-arcillosa (49,57\%). El tamizado de las arenas denota el predominio claro de las partículas finas $(26,73 \%)$ sobre las medias $(19,3 \%)$ y las gruesas $(4,4 \%)$. Por otro lado, los parámetros estadísticos arrojan valores bajos al situarse en la fracción fina $(\mathrm{Md}=192 \mu)$ y en el umbral de las medias $\left(\mathrm{M}_{\mathrm{z}}=226 \mu\right)$, de lo que se deduce una baja competencia de arrastre o bien una disminución si se compara con las cifras del nivel $\mathrm{T}_{1}$. Por último, cabe destacar que estos materiales están de moderadamente clasificados $\left(\sigma_{\Phi}=0,99 \Phi\right)$ a bien clasificados $\left(S_{0}=1,32 \Phi\right)$, con una curva acumulativa simétrica $\left(\mathrm{Sk}_{\mathrm{I}}=-0,074 \Phi\right)$, mesocúrtica $\left(\mathrm{K}_{\mathrm{G}}=0,52 \Phi\right)$ y de trazado ligeramente hiperbólico (figura 4).

Hay otro retazo de la $\mathrm{T}+60 \mathrm{~m}$ en la margen izquierda del río Ribeles. Se trata de un replano de escasas dimensiones caracterizado por el afloramiento, en un pequeño corte, de gravas y cantos rodados inmersos en una matriz fina (figuras 2 y 3 ).

Nivel de terraza fluvial $+42-50 m\left(T_{3}, 177-185 m\right.$ s.n.m. $)$

Esta terraza se localiza en la margen izquierda del río Ribeles. Adopta una disposición estrecha y alargada, cuenta con una suave inclinación hacia el cauce, presenta un nítido escarpe de terraza y su estructura se puede ver en dos puntos. En ambos casos se perciben gravas y cantos fundamentalmente cuarcíticos y completamente rodados, pero su escasa entidad impide la realización de análisis de la fracción gruesa.

La matriz, de color amarillo marrón (10 YR 6/6), es bastante más arenosa (62,53\%) que limo-arcillosa (37,47\%). La distribución de las arenas muestra un predominio de las partículas finas $(26,2 \%)$ y medias (25\%) sobre las grue- 
sas $(11,3 \%)$. El tamaño medio de los granos es moderado $\left(M_{z}=314 \mu\right)$ al igual que la mediana $(M d=245 \mu)$, señalando una competencia de arrastre notable. No obstante se trata de un depósito de moderadamente clasificado $\left(\mathrm{S}_{0}=1,5 \Phi\right)$ a mal clasificado $\left(\sigma_{\Phi}=1,3 \Phi\right)$, aunque con una curva acumulativa bien proporcionada, esto es, simétrica $\left(S_{\mathrm{I}}=-0,03 \Phi\right)$, mesocúrtica $\left(\mathrm{K}_{\mathrm{G}}=0,52 \Phi\right)$ y de trazado muy rectilíneo pero con fuerte inflexión a partir de $0,5 \mathrm{~mm}$.

Nivel de terraza fluvial $+20-22 m\left(T_{4}, 155-157 m\right.$ s.n.m. $)$

Separado de la terraza $+42-50 \mathrm{~m}$ por un acentuado escarpe, este nivel adosado a la margen izquierda del Ribeles se caracteriza por la buena preservación de sus formas y su gran extensión longitudinal. Tanto es así, que gran parte de la villa de Arenas está construida sobre él. A través de tres cortes hemos efectuado análisis sedimentológicos de la fracción gruesa y fina. El primero de ellos se localiza en la margen izquierda del Ribeles a la altura de la iglesia de Santa María de Llas, el segundo en las inmediaciones de La Panera, a escasos metros del comienzo de la carretera comarcal AS-345 y, por último, el tercero corresponde al depósito cementado de Piélagos, situado en la margen izquierda del río Cares a la altura del pozo de Piedragoneru de Arriba.

En las tres estaciones analizadas se aprecia una distribución granulométrica bimodal con un máximo en la secuencia dimensional 4-6 cm y otro en el intervalo $24-40 \mathrm{~cm}$. También llama la atención el elevado valor de la mediana comprendida entre 10,2 y 10,7 cm, perteneciente al grupo de cantos medianos, la gran dimensión de los centilos (oscilan entre 76,5 y $165 \mathrm{~cm}$ ), así como la amplia longitud de los histogramas, con cotas de recorrido que llegan hasta los $80 \mathrm{~cm}$ y $100 \mathrm{~cm}$ (figura 5). Estas cifras revelan una corriente hídrica caracterizada por una gran competencia de arrastre, propia más bien de un régimen torrencial.

El estudio morfométrico corrobora la elevada energía e intensidad del accionamiento, que se infiere a partir de los bajos valores del aplanamiento (medianas entre 1,66 y 2), fuerte disimetría (con valores entre 591 a 622) y desgaste acusado (mediana entre 221 y 250 sobre cuarcitas y 442 en calizas) (figura 6).

Con respecto a la fracción fina, en Sta. María de Llas la matriz es arenosa (71,47\%), de color amarillo marrón (10 YR 6/6) y con escaso contenido de limos y arcillas (28,53\%). Dentro de las arenas abundan las medias $(33,73 \%)$ y las finas (21,73\%), mientras que las gruesas representan un 16,01\%. El calibre 
FIGURA 5

HISTOGRAMAS GRANULOMÉTRICOS

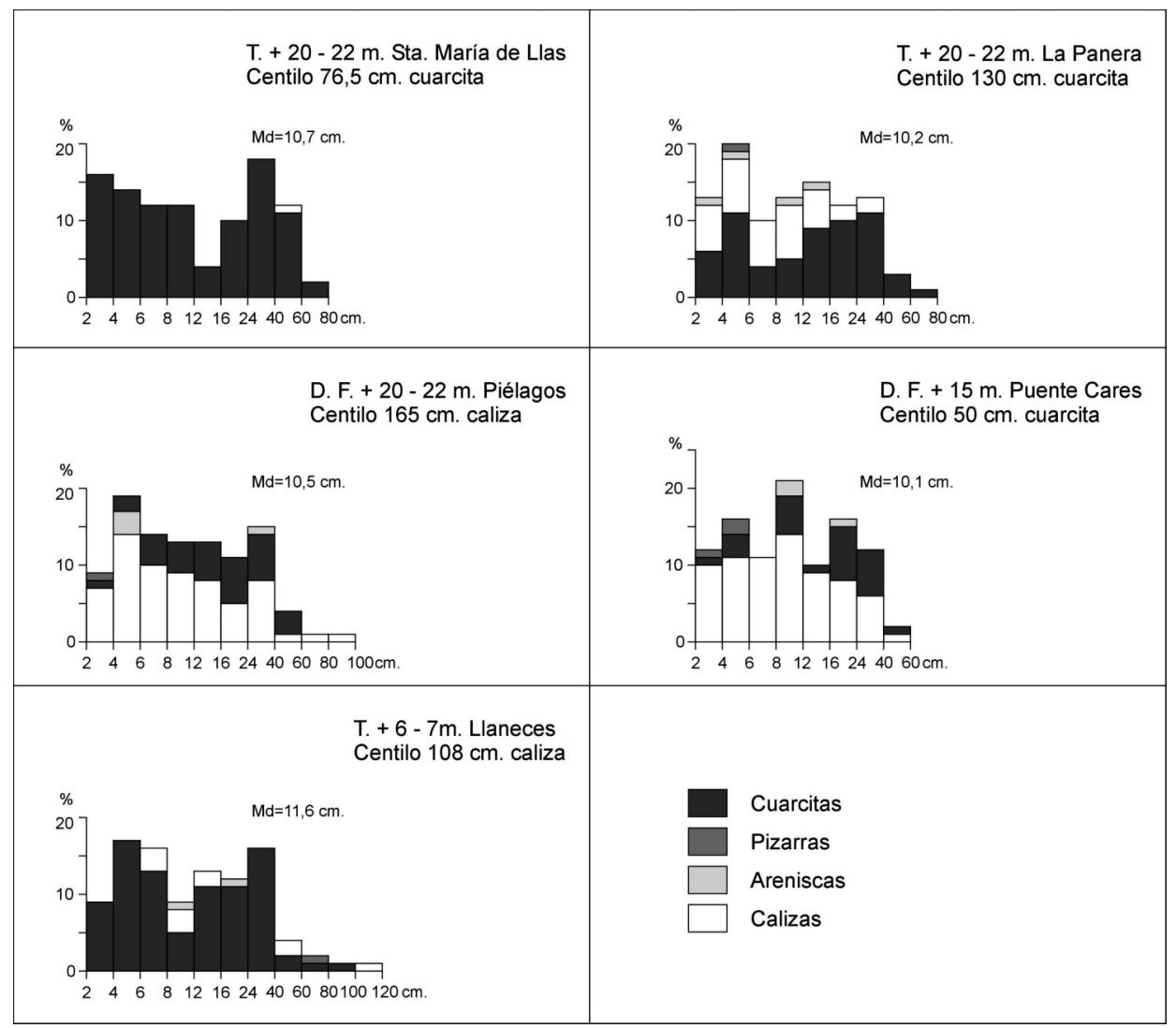

medio de las partículas y el valor central son de moderados a altos $\left(M_{z}=355 \mu\right.$ y $\mathrm{Md}=295 \mu$ ). El resultado es un depósito relativamente clasificado según los índices estadísticos $\left(S_{0}=1,03 \Phi\right.$ y $\left.\sigma_{\Phi}=1,1 \Phi\right)$, con una curva acumulativa de tendencia sigmoidal poco evolucionada, simétrica $\left(\mathrm{Sk}_{\mathrm{I}}=0,08 \Phi\right)$ y ligeramente apuntada, a saber, leptocúrtica $\left(\mathrm{K}_{\mathrm{G}}=0,54 \Phi\right)$ (figura 4).

En la estación de La Panera, la matriz destaca por su color marrón oscuro (7,5 YR 5/6) y textura muy arenosa, con un predominio de los componentes de tamaño medio $(57,3 \%)$, sobre los gruesos $(11,57 \%)$ y los finos $(23,43 \%)$. Esto explica que tanto el tamaño medio de las partículas como el valor central 
FigURA 6

HISTOGRAMAS MORFOMÉTRICOS DE DESGASTE, APLANAMIENTO Y DISIMETRÍA

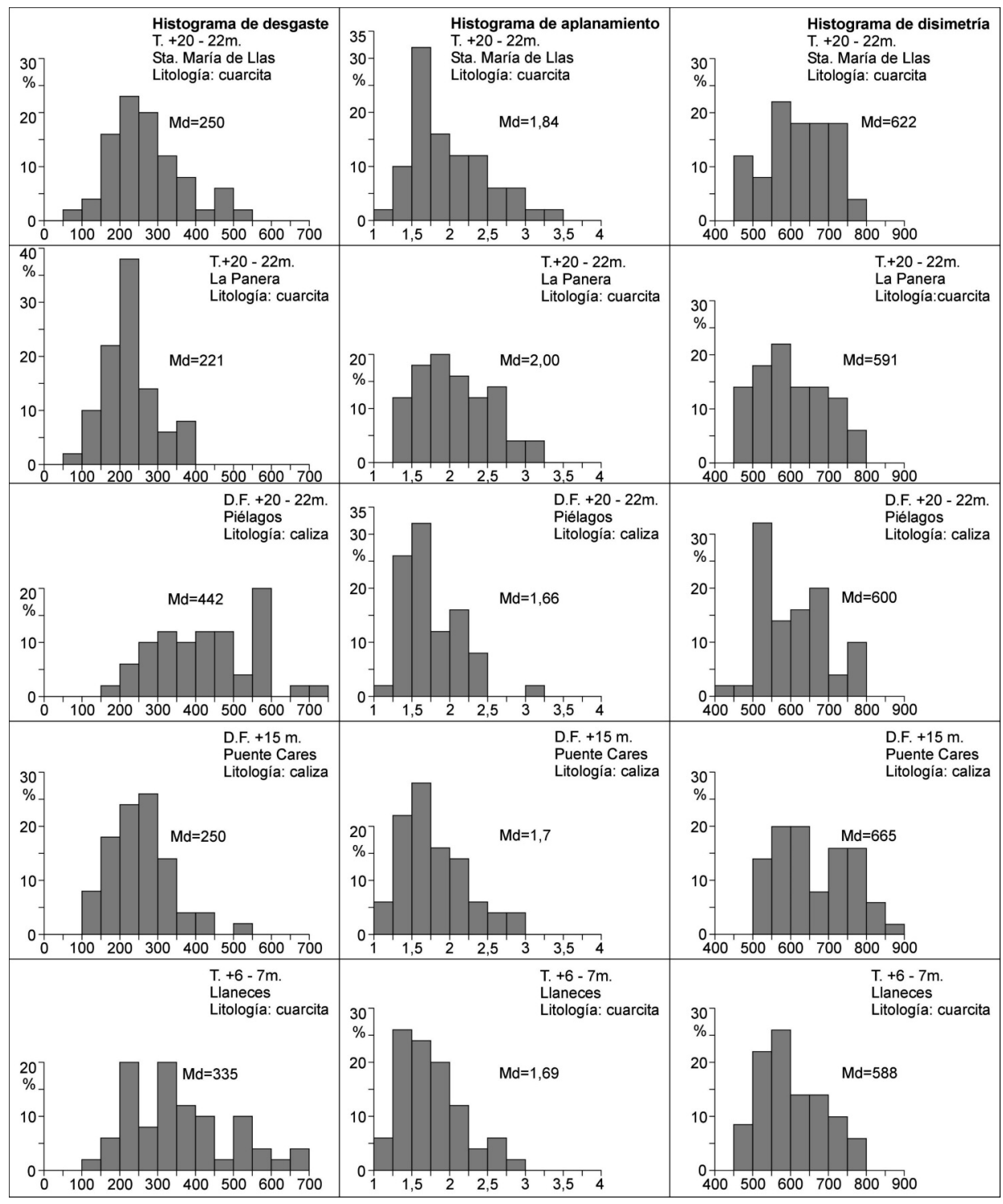

Estudios Geográficos, Vol. LXXII, 270, pp. 173-202, enero-junio 2011

ISSN: 0014-1496, eISSN: 1988-8546, doi: 10.3989/estgeogr.201108 
de la distribución se integren en la secuencia de arenas medias $\left(M_{z}=306 \mu\right.$ y $\mathrm{Md}=289 \mu$ ). Otra característica de este depósito es su buena clasificación atestiguada por las cifras que señalan los diversos índices de selección $\left(\mathrm{S}_{0}=1,3 \Phi\right.$ y $\left.\sigma_{\Phi}=0,8 \Phi\right)$. Por último, la curva acumulativa es simétrica $\left(\mathrm{SK}_{\mathrm{I}}=0,08 \Phi\right)$, ligeramente apuntada, es decir, leptocúrtica $\left(\mathrm{K}_{\mathrm{G}}=0,54 \Phi\right)$ y con un trazado de tendencia ligeramente sigmoidal, al disponer de una alta proporción de materiales gruesos.

En el depósito de Piélagos, la matriz que empasta la fracción grosera tiene una tonalidad amarilla marrón (10 YR 6/6) y es básicamente arenosa (73,3\%). La proporción de arenas finas es pequeña $(12,6 \%)$, frente a las medias (32\%) y gruesas $(28,7 \%)$. En consecuencia, el tamaño medio de las partículas es elevado $\left(\mathrm{M}_{\mathrm{z}}=486 \mu\right)$ al igual que la mediana $(\mathrm{Md}=410 \mu)$, lo que implica un incremento de la competencia de arrastre si se compara con las terrazas altas. Los índices granulométricos revelan que estos materiales aluviales están moderadamente clasificados según el índice de Trask $\left(\mathrm{S}_{0}=1,8 \Phi\right)$ y de moderadamente a mal clasificados según la desviación típica $\left(\sigma_{\Phi}=1,1 \Phi\right)$. Por último, la curva acumulativa presenta un trazado parabólico evolucionado en su tramo superior, tratándose, no obstante, de una distribución simétrica $\left(\mathrm{Sk}_{\mathrm{I}}=0,03 \Phi\right)$ y ligeramente platicúrtica $\left(\mathrm{K}_{\mathrm{G}}=0,53 \Phi\right)$ (figura 4).

Nivel de terraza fluvial $+14-17 m\left(T_{5}, 149-152 m\right.$ s.n.m. $)$

Se compone de un único resto que se extiende entre la pradería de la Vega y el barrio de Moradiellos. Se caracteriza por tener una ligera inclinación hacia el río Casaño y escarpes desiguales. No hemos encontrado ningún corte y sólo es posible reconocer en superficie algunos cantos aislados. Sin embargo, en el Puente Cares hay un depósito fluvial que corresponde a este mismo nivel, pues está colgado a $+15 \mathrm{~m}$, y en él hemos podido llevar a cabo análisis sedimentológicos.

El histograma granulométrico presenta una distribución trimodal, con un máximo en 8-12 cm (cantos medianos), otro en 4-6 cm (cantos pequeños) y un tercero en 16-24 cm (cantos grandes), lo que evidencia la escasa selección de los materiales transportados (figura 5). El alto valor de la mediana (10,1 $\mathrm{cm}$ ), el gran tamaño del centilo y la amplia cota de recorrido (hasta $60 \mathrm{~cm}$ ), indican una escorrentía con una dinámica muy enérgica y de alta capacidad de arrastre. Además, destaca el elevado grado de desgaste (mediana de 250), el bajo índice de aplanamiento $(1,7)$ y la acusada disimetría $(665)$, por lo que los datos morfométricos también arrojan cifras propias de una corriente de connotaciones torrenciales (figura 6). 
El depósito tiene una elevada proporción de gravas, puesto que al analizar la matriz, la fracción de rechazo ( $\geq 2 \mathrm{~mm}$ ) representa el $74 \%$ de la muestra tomada. Dicha matriz es color marrón amarillento (10 YR 5/6). Desde el punto de vista granulométrico la fracción arenosa es muy abundante $(61,77 \%)$, frente a los limos y arcillas (38,23\%). El tamizado de las arenas revela el reparto casi equitativo entre partículas finas $(26,9 \%)$, gruesas $(19,97 \%)$ y medias $(14,9 \%)$. Por tanto, el tamaño medio de las arenas y de la mediana se sitúa en la secuencia de las arenas medias $\left(M_{z}=435 \mu\right.$ y $\left.M d=250 \mu\right)$, denotando una curva disimétrica ligada al predominio de las fracciones medias y gruesas sobre las finas $\left(\mathrm{SK}_{\mathrm{I}}=-0,17 \Phi\right)$. El resultado es un depósito mal clasificado como lo expresan tanto los índices estadísticos de selección $\left(\sigma_{\Phi}=1,5 \Phi\right.$ y $\left.\mathrm{S}_{0}=2,2 \Phi\right)$ como el trazado logarítmico de la curva acumulativa (figura 4).

Nivel de terraza fluvial $+12 m\left(T_{6}, 147\right.$ m s.n.m. $)$

Este nivel consta de un único resto de planta irregular situado en la margen derecha del río Casaño, en la pradería de Panderrieses. No hay ningún corte que permita realizar análisis de detalle y sólo se observan algunos cantos rodados en superficie. Presenta un escarpe de terraza bastante acentuado en su borde occidental y más difuminado hacia el sector oriental (figuras 2 y $3)$.

Nivel de terraza fluvial $+8-10 m\left(T_{7}, 143-145\right.$ m s.n.m. $)$

Está integrado por cuatro retazos. El primero se halla en la margen izquierda del río Casaño a la altura del barrio de Moradiellos. El segundo es una amplísima terraza, alargada de Este a Oeste, que se extiende desde la confluencia del río Ribeles con el Casaño hasta el pozo de Piedragoneru de Arriba, y que está incidida en la parte central por el arroyo Vau Ranu (figuras 2 y 3). No hay ningún corte que muestre su estructura y sólo se ven cantos aislados en superficie y en su escarpe. El tercer retazo está inmediatamente al Sur de la confluencia del río Casaño con el Cares. Sobre este replano, en cuyo interior se alza el barrio de Cares, aparecen esparcidos cantos rodados. El último retazo del nivel se ubica al Sureste del sistema de terrazas, a saber, en la margen derecha del río Cares, y sobre él se ha construido parte de un camping. 
Nivel de terraza fluvial +6-7 m( $T_{8}, 141-142$ m s.n.m. $)$

Está representado exclusivamente por la terraza de Llaneces, situada al Noroeste de la confluencia del río Casaño con el Cares. Las excavaciones efectuadas para construir los cimientos de dos bloques de viviendas nos han permitido analizarla.

Desde el punto de vista litológico se caracteriza, a diferencia del Puente Cares, por el predominio de las cuarcitas sobre las calizas. En el histograma granulométrico destaca la mala clasificación de los elementos, con una distribución bimodal muy marcada (máximos en 4-6 y 24-40 cm) y valores muy altos de la mediana $(11,6 \mathrm{~cm})$ y del centilo $(108 \mathrm{~cm})$. Respecto a la morfometría, el desgaste de los cantos es muy intenso, con una mediana de 335 y un $20 \%$ de los cantos con un desgaste superior a 500; el aplanamiento es muy bajo $(1,69)$ y la disimetría muy elevada (588) (Figuras 5 y 6). Por tanto los parámetros granulométricos y morfométricos son superiores incluso a los otros niveles e indicativos de un comportamiento torrencial muy enérgico, incapaz de seleccionar los materiales y de acusado accionamiento.

Al igual que el nivel $\mathrm{T}_{5}+14-17 \mathrm{~m}$, este depósito tiene una gran cantidad de gravas, puesto que el rechazo de textura $(\geq 2 \mathrm{~mm})$ al analizar la matriz fina supera el $95 \%$ de la muestra. Por otro lado, el análisis granulométrico de la fracción arenosa muestra una disminución porcentual conforme aumenta el tamaño de las partículas, ya que las arenas gruesas suponen el $15,43 \%$, las medias el $20,1 \%$ y las finas el $21,1 \%$. El tamaño medio sigue siendo alto, esto es, dentro de las arenas medias $\left(\mathrm{M}_{\mathrm{z}}=371 \mu\right.$ y $\left.\mathrm{Md}=276 \mu\right)$; no obstante se trata de un depósito de moderado a mal clasificado $\left(\sigma_{\Phi}=1,4 \Phi\right.$ y $\left.\mathrm{S}_{0}=1,7 \Phi\right)$, con una curva acumulativa logarítmica con una ligera inflexión a partir de 0,80 $\mathrm{mm}$, que indica una escasa selección de las partículas, aunque con una distribución simétrica $\left(\mathrm{SK}_{\mathrm{I}}=-0,04 \Phi\right)$ y curva mesocúrtica $\left(\mathrm{K}_{\mathrm{G}}=0,49 \Phi\right)$ (figura 4).

Nivel de terraza fluvial $+5 m\left(T_{9}, 140\right.$ m s.n.m. $)$

Se trata de una única terraza con forma estrecha y alargada situada en la margen derecha del río Cares (área meridional del sistema de terrazas), cerca de Valdelabarca. No hay ningún corte y sólo se aprecian algunos cantos aislados de caliza y cuarcita esparcidos por su superficie. 


\section{Cronología de las terrazas fluviales}

En una excavación efectuada con motivo de la construcción de un bloque de viviendas en el barrio de Moradiellos (Arenas de Cabrales), hemos realizado una datación radiocarbónica en la $\mathrm{T}+8-10 \mathrm{~m}$. De techo a muro la secuencia estratigráfica de dicha terraza se compone de 3 niveles. El primero (N1), de 0,60 m de espesor medio, se caracteriza por la abundancia de materia orgánica (con la excavación este nivel orgánico fue retirado en toda la extensión de la parcela a construir); a continuación se encuentra el N2, que alcanza un espesor medio de 2,15 m y está compuesto por cantos rodados decimétricos de cuarcita, imbricados e inmersos en una matriz arenosa de tonos pardos; finalmente aflora un nivel arenoso (N3) de 1,50 m de potencia visible, que hacia la base es cada vez más arcilloso, en el que están englobadas pequeñas gravas rodadas de naturaleza cuarcítica. La muestra datada (carbón vegetal) se recogió en el N3, concretamente $15 \mathrm{~cm}$ por debajo de los cantos rodados que integran el N2 y a una profundidad total de $2,90 \mathrm{~m}$. La edad radiométrica obtenida es de $37.300 \pm 800$ años BP (cuadro 2).

Por su parte, en otra excavación abierta con motivo de la construcción de otro bloque de viviendas se ha datado igualmente carbón vegetal en un depósito perteneciente a la $\mathrm{T}+20-22 \mathrm{~m}$ y situado en la margen derecha del río Ribeles. La edad obtenida es anterior a 48.000 años BP, es decir, la muestra es más antigua que el rango del $\mathrm{C}^{14}$. En cualquier caso este dato supone una edad mínima para el nivel +20-22 m y demuestra que los mencionados niveles fluviales tienen mayor antigüedad que otros de similares cotas datados en ríos cantábricos cercanos, como se expondrá posteriormente.

En Praón, enclave situado en la confluencia del arroyo homónimo con el río Cares unos $3 \mathrm{~km}$ al Sur de Arenas de Cabrales, destaca un retazo de cono de deyección colgado en la margen izquierda de dicho arroyo a unos $22 \mathrm{~m}$ sobre el nivel actual del cauce (figura 7). Está compuesto por gravas, cantos y bloques subredondeados y subangulosos de cuarcita y caliza, que se hallan envueltos en una matriz fina de textura arenoso-limosa y están ligeramente cementados a techo en algunos sectores. El citado retazo de abanico torrencial se encuentra fosilizado por derrubios homométricos, angulosos, estratificados e intensamente cementados. En efecto, se aprecia una alternancia de gravas y pequeños cantos de caliza de formas aristadas, orientados de acuerdo con la inclinación de la pendiente (unos $20^{\circ}$ ), y fuertemente cohesionados con posterioridad por un cemento calcáreo. Dichos derrubios presentan un espesor visible de unos $4 \mathrm{~m}$ y tienen gran continuidad lateral, puesto que se extienden a los pies de gran parte de la vertiente meridional de la pequeña Sierra de Do- 
FIGURA 7

VISTA DEL CONO TORRENCIAL DE PRAÓN (C1), COLGADO A 22 m SOBRE EL CAUCE ACTUAL Y FOSILIZADO POR DERRUBIOS ESTRATIFICADOS Y

CEMENTADOS (DE). EN LA MARGEN DERECHA DEL ARROYO SE APRECIAN

OTROS DOS RETAZOS DE CONOS DE DEYECCIÓN ENCAJADOS (C2 Y C3), ELEVADOS RESPECTIVAMENTE A 10 Y 5 M DE ALTURA SOBRE EL RÍO CARES

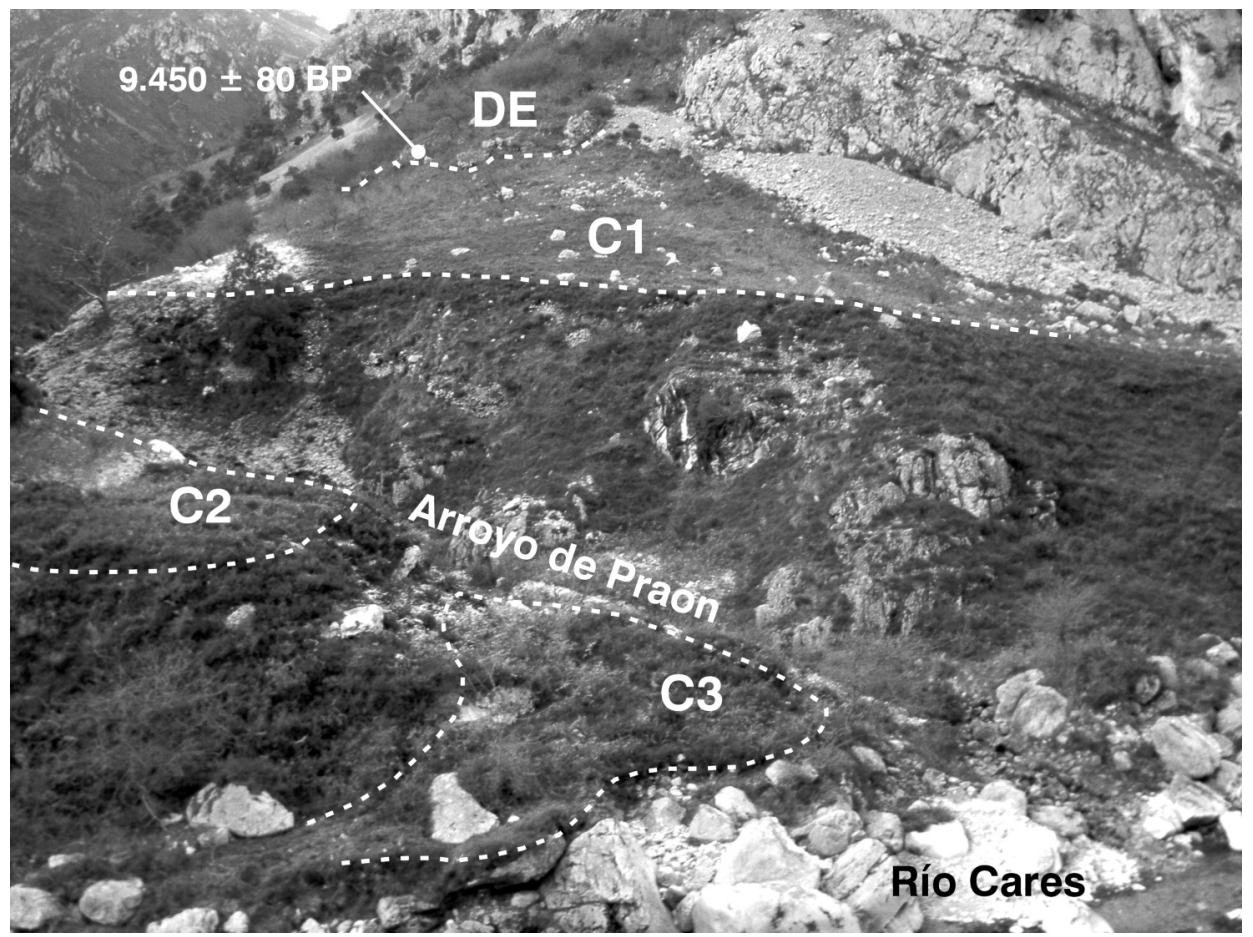

bros, y a su vez están fosilizados en numerosos sectores por canchales actuales. La muestra datada, compuesta por restos de caracoles, se recogió en los mencionados derrubios a $4 \mathrm{~m}$ de profundidad y arrojó una edad de $9.450 \pm 80$ años BP (cuadro 2). Debido a la gran profundidad a la que han sido encontrados dentro del depósito, nuestra hipótesis es que dichos caracoles son sincrónicos a la formación de los derrubios, y sin duda anteriores a la deposición del cemento calcáreo. En consecuencia la morfogénesis de estas gravas se corresponde con el final del Pleistoceno superior y los inicios del Holoceno. La cronología obtenida en los derrubios estratificados constituye además una edad 
mínima para el retazo de abanico torrencial fosilizado y, en consecuencia, para el nivel de terraza $+20-22 \mathrm{~m}$ del río Cares.

Finalmente hemos efectuado también otra datación en un cauce muy próximo (el Sella), que incluimos en este trabajo, pues aporta una edad mínima para la $\mathrm{T}+10 \mathrm{~m}$ de dicho río. A lo largo del valle medio y bajo del río Sella algunas terrazas de los niveles inferiores $(+8 \mathrm{y}+10 \mathrm{~m})$ se hallan fosilizadas por abanicos torrenciales cuya génesis se debe al desmantelamiento parcial de las vertientes regularizadas por acumulación que tapizan los afloramientos cuarcíticos y/o de los derrubios estratificados y cementados que se localizan a los pies de los materiales calcáreos. Uno de estos conos ha sido datado mediante $\mathrm{C}^{14}$. Se localiza en la zona conocida como El Cabezu-Les Estayes (inmediaciones de Las Rozas), fosiliza a la $\mathrm{T}+10 \mathrm{~m}$ del río Sella y está siendo explotado actualmente por una cantera (figura 8). Un corte cuyo espesor visible máximo es de $30 \mathrm{~m}$ deja ver la estructura del depósito, compuesto principalmente por gravas de naturaleza cuarcítica, estratificadas, angulosas y englobadas en una matriz arenosa, entre las que aparece intercalado sedimento orgánico y restos vegetales, especialmente a techo. La muestra datada se recogió a una profundidad de $25 \mathrm{~m}$ y ha dado una antigüedad de $2.625 \pm 55$ años BP (cuadro 2), denotando en consecuencia el carácter reciente de los mencionados conos y ofreciendo a su vez una edad mínima para la $\mathrm{T}+10 \mathrm{~m}$ del río Sella.

\section{DisCUSIÓN}

El estudio sedimentológico de los depósitos fluviales revela que la descarga hidrológica de estos ríos, y especialmente la del Cares, ha sido muy enérgica, con alta capacidad de arrastre y escasa selección de los materiales, propia de un comportamiento general de tipo torrencial que, tal y como señalan diversos autores (Edeso y Ugarte, 1987; Agudo et al., 1988; González Amuchastegui, 2000; Edeso, 2006), es común en los ríos de la vertiente Norte de la Cordillera Cantábrica. No obstante se distinguen claramente dos fases. En la primera se modelan las terrazas más altas (+90 m y +60 m), que están escalonadas y colgadas y definidas por su escaso grosor, estructura masiva y textura de soporte matricial. Los parámetros estadísticos evidencian una competencia de arrastre moderada que se atenuó más durante la morfogénesis de la $\mathrm{T}+60$ $\mathrm{m}$. En cambio, a partir del nivel $\mathrm{T}_{3}$ se inicia un período definido por un incremento significativo de la carga detrítica y un aumento progresivo de la competencia de las corrientes hídricas; alcanzando en los niveles $T_{4}$ a $T_{8}$ un comportamiento hidrodinámico netamente torrencial como se aprecia en los 


\section{FIGURA 8}

ESQUEMA Y PERFIL GEOMORFOLÓGICOS DEL RÍO SELLA EN LAS INMEDIACIONES DE LAS ROZAS QUE MUESTRAN LA RELACIÓN ESTRATIGRÁFICA ENTRE EL CONO TORRENCIAL DATADO Y LA T +10 m DE EL CABEZU-LES ESTAYES
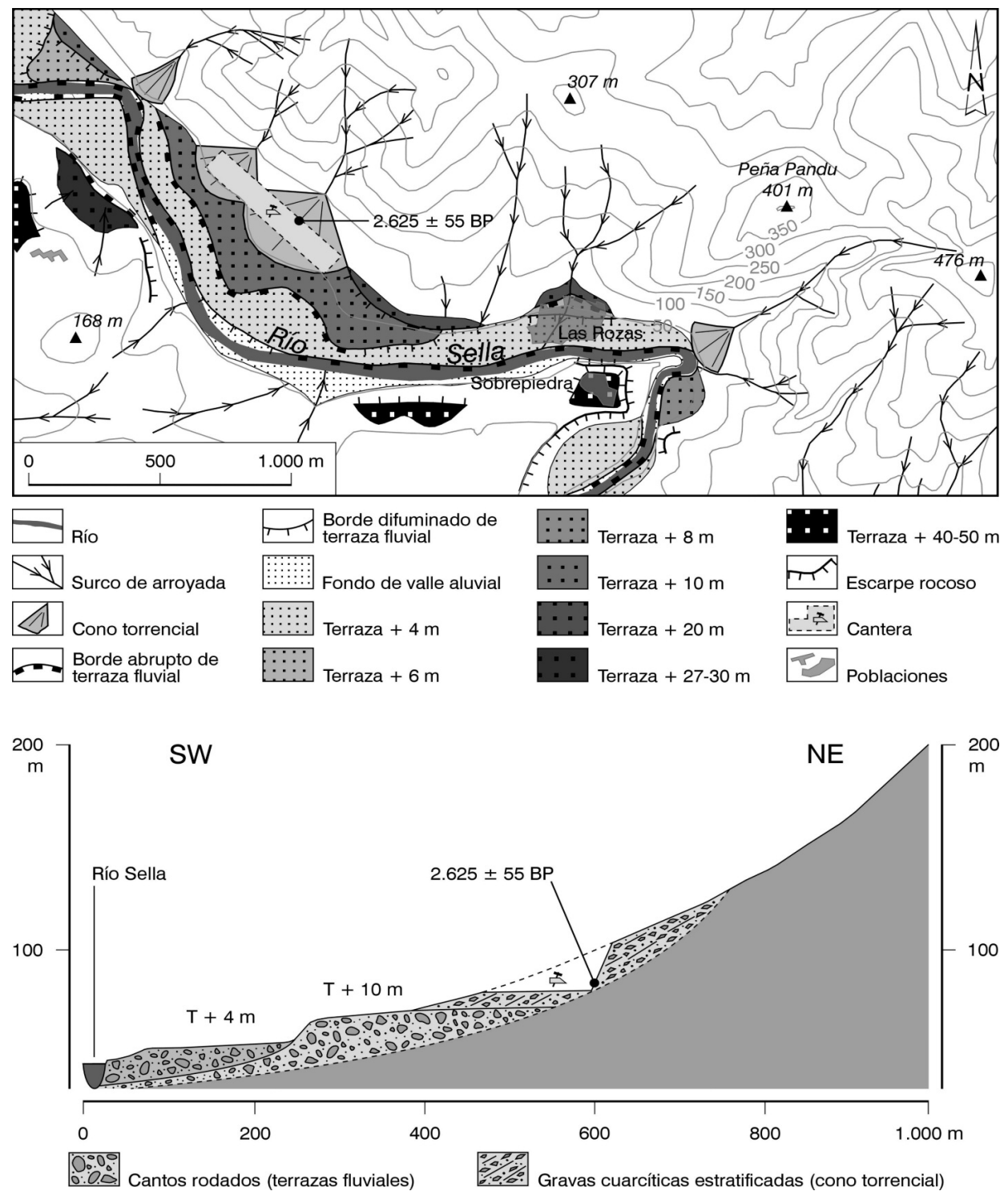

Estudios Geográficos, Vol. LXXII, 270, pp. 173-202, enero-junio 2011 ISSN: 0014-1496, eISSN: 1988-8546, doi: 10.3989/estgeogr.201108 
siguientes parámetros estadísticos: histogramas granulométricos bimodales (e incluso trimodales) y con amplias cotas de recorrido $(120 \mathrm{~cm})$, depósitos masivos y mal clasificados $\left(\sigma_{\Phi}=1,5 \Phi\right)$, curvas granulométricas mayoritariamente de facies logarítmicas e índices de disimetría $(\mathrm{Md}=665)$ y de desgaste $(\mathrm{Md}=442)$ muy elevados.

Estas dos fases diferenciadas en el comportamiento hidrodinámico del río Cares y sus afluentes sugieren la existencia de condiciones climáticas de mayor estabilidad en el primer caso y más frías en el segundo, lo que favorecería una activa dinámica de vertientes y consecuentemente la abundancia de aportes laterales. Se ha constatado la existencia de periodos fríos en la Cordillera Cantábrica desde fechas anteriores a 30.000 años BP, hasta hace 10.000 años BP (Jiménez y Farias, 2002; González Trueba, 2007; Moreno et al., 2010). Sin embargo, además del factor climático, que contribuiría a explicar el aumento detectado en el tamaño y el volumen de los acarreos, es necesario tener en cuenta otros que también intervienen en el comportamiento hidrodinámico y/o en la tasa de incisión de estos ríos cantábricos como la tectónica y por supuesto el eustatismo. De hecho, los cambios climáticos y eustáticos están íntimamente relacionados. Así, según Mary (1983) y Cearreta, Edeso y Ugarte (1992), durante el Último Máximo Glaciar (LGM) el mar llegó a descender al menos 100 m por debajo del nivel actual, causando la excavación de los tramos finales de los ríos y sus consiguientes repercusiones en el perfil de equilibrio. Según Mary (1983) en la ría de Tina Mayor (desembocadura del Cares-Deva), el sustrato está a $-45 \mathrm{~m}$. Con respecto al factor tectónico, cabe destacar el progresivo ascenso experimentado por la costa cantábrica desde el Terciario (Flor, 1983; Mary, 1983), lo que sin duda ha provocado un descenso sucesivo del nivel de base de los ríos de dicha región. Mediante la datación de espeleotemas en la Cueva del Pindal (Oriente de Asturias), Jiménez et al. (2006) sugieren una tasa de elevación del Margen Cantábrico en esta zona de $0,19 \mathrm{~mm} /$ año.

En relación con la edad de las terrazas del río Cares, se ha de señalar la ausencia de trabajos previos sobre las industrias líticas y la falta de indicios pa leontológicos, por lo que hemos establecido la cronología de 2 niveles de terraza mediante dataciones de $\mathrm{C}^{14}$ en los propios sedimentos fluviales o en otros depósitos que los fosilizan. Destaca la obtención de una edad radiométrica para la $\mathrm{T}_{7}(+8-10 \mathrm{~m})$ de $37.300 \pm 800$ años BP y de una antigüedad mínima para la $\mathrm{T}_{4}(+20-22 \mathrm{~m})$ de 48.000 años BP. Asimismo, se han obtenido otras dos edades mínimas acordes con las anteriores de $9.450 \pm 80$ años BP para el nivel $+20-22 \mathrm{~m}$ del Cares y de $2.625 \pm 55$ años BP para la $\mathrm{T}+10 \mathrm{~m}$ del Sella. Cabe citar que la sedimentación de la $\mathrm{T}+8-10 \mathrm{~m}$ del Cares coincide con el inicio del retroceso glaciar en los Picos de Europa, fechado en 38.000 años 
BP en la base de un sondeo efectuado en los depósitos glaciolacustres del Lago Enol (Moreno et al., 2010). En cambio, como se ha puesto de manifiesto anteriormente, las edades radiocarbónicas aportadas por González et al. (1996) para el nivel de terraza $+10 \mathrm{~m}$ de los ríos Pas y Besaya son bastante más recientes, concretamente de $2.720 \pm 60$ años BP y de $2.780 \pm 80$ años BP, mientras que la $\mathrm{T}+15 \mathrm{~m}$ y la $\mathrm{T}+20 \mathrm{~m}$ del Pas tendrían respectivamente $4.900 \pm 100$ años BP y $5.490 \pm 90$ años BP. Según las edades logradas por estos autores, los citados niveles de terraza serían holocenos.

A partir de la edad obtenida para la $\mathrm{T}+8-10 \mathrm{~m}$ del Cares se infiere una tasa de incisión de este río en los últimos 37.000 años de 0,24 mm/año. Aunque debe ser entendida como un resultado preliminar, esta tasa es similar a la tasa media de levantamiento del Margen Cantábrico propuesta por Jiménez et al. (2006) para la zona oriental de Asturias ( $0,19 \mathrm{~mm} / \mathrm{año})$, y a la tasa media de incisión establecida por Smart (1986) para la garganta del río Urdón (Picos de Europa) mediante la datación de espeleotemas $(0,3 \mathrm{~mm} / \mathrm{año})$. Por su parte, el promedio de incisión de los ríos Pas y Besaya durante los últimos 2.800 años es bastante más alto, concretamente de 3,64 mm/año (González et al., 1996). Según estos mismos autores la tasa media de encajamiento de los citados ríos desde hace 100.000 años es de $0,5 \mathrm{~mm} / \mathrm{año}$. El decrecimiento temporal en el promedio de la tasa de incisión no debe sorprendernos, ya que por ejemplo pulsaciones de levantamiento tectónico que pueden ser significativas en escalas temporales cortas, reactivando la incisión, no lo son tanto en escalas temporales largas en las que también hay extensos periodos de calma tectónica, tal y como se cita en el trabajo de Cunha et al. (2008), en el que se aportan unas tasas de encajamiento para el río Tajo a su paso por el área de Ródão (Portugal) de 0,52 mm/año en los últimos 31.000 años, de $0,24 \mathrm{~mm} /$ año desde hace 100.000 , y aproximadamente de $0,07 \mathrm{~mm} /$ año durante los últimos 2,6 millones de años.

A la espera de realizar nuevas dataciones que complementen las aportadas en este trabajo, los resultados cronológicos y sedimentológicos obtenidos sugieren que las terrazas bajas del río Cares (al menos de la $\mathrm{T}+6-7 \mathrm{~m}$ a la $\mathrm{T}+20-$ $22 \mathrm{~m}$ ), caracterizadas por estar embutidas o encajadas, por la masividad de sus materiales y por la gran competencia de las corrientes hídricas que las depositaron, serían contemporáneas al último ciclo glaciar pleistoceno, importante recrudecimiento climático que posibilitó la formación de glaciares en numerosos sectores de las montañas cantábricas, entre otros ámbitos. En este sentido, en los valles de los ríos Cinca y Gállego (Pirineos centrales) Lewis et al. (2009) señalan la existencia de importantes periodos de aluvionamiento responsables de la génesis de varios niveles de terraza, que coinciden también con fases frías. 
En cambio las terrazas altas (al menos los niveles +90 y +60 m) serían anteriores al último ciclo glaciar y modeladas en un contexto climático de mayor estabilidad, lo que contribuiría a explicar, junto con el resto de factores mencionados, el predominio de texturas de soporte matricial, la menor competencia de arrastre de las corrientes que las modelaron, así como la hegemonía de la incisión sobre la deposición de materiales.

\section{CONCLUSIONES}

En la depresión de Arenas de Cabrales, donde confluyen el río Cares y sus afluentes el Casaño y el Ribeles, se han identificado nueve niveles de terraza situados a las siguientes altitudes relativas sobre el cauce: $\mathrm{T}_{1}+90 \mathrm{~m}, \mathrm{~T}_{2}+60 \mathrm{~m}$, $\mathrm{T}_{3}+42-50 \mathrm{~m}, \mathrm{~T}_{4}+20-22 \mathrm{~m}, \mathrm{~T}_{5}+14-17 \mathrm{~m}, \mathrm{~T}_{6}+12 \mathrm{~m}, \mathrm{~T}_{7}+8-10 \mathrm{~m}, \mathrm{~T}_{8}+6-7 \mathrm{~m} \mathrm{y}$ $\mathrm{T}_{9}+5 \mathrm{~m}$.

Los resultados de los análisis sedimentológicos y las dataciones de $\mathrm{C}^{14}$ realizadas indican que las terrazas bajas, por lo menos de la $\mathrm{T}+6-7 \mathrm{~m}$ a la $\mathrm{T}+20-$ $22 \mathrm{~m}$, depositadas por unas corrientes hídricas de connotaciones torrenciales y caracterizadas por la gran masividad de los materiales transportados, son contemporáneas al último ciclo glaciar pleistoceno. En cambio las terrazas más altas (al menos la $\mathrm{T}+60 \mathrm{~m}$ y la $\mathrm{T}+90 \mathrm{~m}$ ), definidas por una competencia de arrastre moderada, serían anteriores y modeladas en unas condiciones climáticas más estables.

Finalmente, a partir de la edad radiométrica obtenida para la $\mathrm{T}+8-10 \mathrm{~m}$, que como se ha señalado coincide con el inicio del retroceso glaciar en los Picos de Europa, se ha calculado una tasa de incisión del río Cares durante los últimos 37.000 años de $0,24 \mathrm{~mm} /$ año.

Recibido: 21/07/2009

Aceptado: 03/03/2010

\section{Bibliografía}

Agudo, C., Meaza, G., Poblete, M. A., Serrano, E. y Ugarte, F. M. (1988): "Aportación al conocimiento geomorfológico de los depósitos aluviales de fondo de valle". Lurralde: Investigación y Espacio, 11, pp. 85-93.

Asensio, I. (1967): "Nivel cuaternario a $80 \mathrm{~m}$ en la margen occidental de la ría del Eo (Zona galaico-astúrica)". Bol. R. Soc. Hist. Nat. (Geol.), 65, pp. 299-315. 
Asensio, I. (1970): "Rasgos geomorfológicos de la zona litoral galaico-astúrica en relación con las oscilaciones glacio-eustáticas”. Estudios Geológicos, vol. XXVI, pp. 29-91.

Asensio, I. y Lombardero, J. M. ${ }^{a}$ (1987): "Contribución al estudio de terrazas fluviales en el valle del Eo (Lugo)". Cuaderno do Laboratorio Xeolóxico de Laxe, 11, pp. 31 36.

Asensio, I. y Nonn, H. (1964a): "Materiales sedimentarios de terrazas fluviales I. Los depósitos de terraza del río Eo y de las márgenes de su ría". Estudios Geográficos, 96, pp. 319-341.

Asensio, I. y Nonn, H. (1964b): "Materiales sedimentarios de terrazas fluviales II. Sedimentos de terrazas y aluviones actuales de los ríos Masma y Oro (Provincia de Lugo)". Estudios Geográficos, 96, pp. 341-366.

Bahamonde, J. R. y Colmenero, J. R. (1993): “Análisis estratigráfico del Carbonífero medio y superior del Manto del Ponga (Zona Cantábrica)". Trabajos de Geología, 19, pp. 155-193.

Bronk Ramsey, C. (2005): "Improving the resolution of radiocarbon dating by statistical analysis", en T. E. Levy y T. F. G. Higham (eds.): The Bible and Radiocarbon Dating: Archaeology, Text and Science. London, Equinox, pp. 57-64.

Cailleux, A. y Tricart, J. (1965): Initiation a l'étude des sables et des galets. París, C. D. U.

Cearreta, A., Edeso, J. M. y Ugarte, F. (1992): "Cambios del nivel del mar durante el Cuaternario reciente en el Golfo de Bizcaia", en A. Cearreta y F. Ugarte (eds.): The late Quaternary in the Western Pyrenean Region. Bilbao, UPV, pp. 57-94.

Cendrero, A., Díaz de Terán, J. R. y Moñino, M. (1988): “Deformación de terrazas fluviales recientes en la franja costera cantábrica". Geogaceta, 4, pp. 21-22.

Cunha, P. P., Martins, A. A., Huot, S., Murray, A. y Raposo, R. (2008): "Dating the Tejo river lower terraces in the Ródão area (Portugal) to asses the role of tectonics and uplift". Geomorphology, 102, pp. 43-54.

Edeso, J. M. (2006): "Caracterización granulométrica, morfométrica, litológica y de las terrazas fluviales del valle del río Oiartzun (Gipuzkoa, País vasco)". Lurralde: Investigación y Espacio, 29, pp. 299-342.

Edeso, J. M. y Ugarte, F. M. (1987): "Los depósitos detríticos cuaternarios del Valle del Río Oyarzun (Guipúzcoa)". Munibe (Ciencias Naturales), 39, pp.103-114.

Estrada, R. y Jordá, J. F. (2003): “Arqueología y gas natural: el Paleolítico medio de El Barandiallu (Villabona, Llanera, Asturias Central)”, en G. Flor (ed.): Actas de la XI Reunión nacional de Cuaternario. Oviedo, AEQUA, pp. 253-260.

Farias, P. (1982): "La estructura del Sector Central de los Picos de Europa". Trabajos de Geología, 12, pp. 63-72.

Fernández-Irigoyen, J. y Ruiz-Fernández, J. (2008): "Prospección geoarqueológica de las terrazas fluviales del río Sella (Oriente de Asturias): el yacimiento de El Caxili". Cuaternario y Geomorfología, 22 (3-4), pp. 173-187.

Fernández, J., Jiménez, M., Arbizu, M., Arsuaga, J. L., Adán, G., Aramburu, A., Aramburu, C., Álvarez, D. y García, M. (2005): "Estudio geoarqueológico preliminar de las terrazas fluviales del río Trubia en el entorno de La Cueva del Conde (Tuñón, 
Asturias, Noroeste de España)", en VI Reunión de Cuaternario Ibérico, Libro de Actas, Gibraltar, pp. 38-39.

Flor, G. (1983): "Las rasas marinas: ensayos de correlación y emplazamiento". Trabajos de Geología, 13, pp. 65-81.

Flor, G., Fernández, L. A. y Cabrera, R. (1993): "Aspectos morfológicos del estuario del Eo". Trabajos de Geología, 19, pp. 75-95.

Folk, R. L. (1980): Petrology of Sedimentary Rocks. Austin, Hemphilds.

Folk, R. L. y Ward, W. L. (1957): "Brazos river bar, a study in the significance of grain size parameters". Jour. Sed. Petr., 27, pp. 3-26.

Frochoso, M. (1990): Geomorfología del valle del Nansa. Santander, Servicio de Publicaciones de la Universidad de Cantabria.

Gómez, M. J. (1983): Geomorfología del occidente asturiano. Tesis Doctoral. Universidad Complutense de Madrid.

González, A., Díaz, J. R., Barba, F. J., Remondo, J. y Cendrero, A. (1996): "Propuesta de un modelo cronológico para las terrazas de los ríos de la vertiente cantábrica". Geogaceta, 20 (5), pp. 1096-1099.

González Amuchastegui, M. ${ }^{a}$ J. (2000): "Evolución morfoclimática del País Vasco durante el Cuaternario: estado de la cuestión". Cuaternario y Geomorfología, 14 (34), pp. 79-99.

González Trueba, J. J. (2007): El paisaje natural del Macizo Central de los Picos de Europa. Santander, Consejería de Medio Ambiente del Gobierno de Cantabria.

Hoyos, M. (1989): "La Cornisa cantábrica", en A. Pérez-González, P. Cabra-Gil, A. Martín-Serrano y J. A. Heras (coords.): Mapa del Cuaternario de España a escala 1:1.000.000. Madrid, ITGE, pp. 105-108.

Jiménez, M. (1999): “Geomorfología fluvial en la cabecera del río Nalón (Cordillera Cantábrica, Noroeste de España)". Trabajos de Geología, 21, pp. 189-200.

Jiménez, M., Bischoff, J., Stoll, H. y Aranburu, A. (2006): "A geochronological approach for cave evolution in the Cantabrian Coast (Pindal Cave, NW Spain)". Zeitschrift für Geomorphologie N. F., 147, pp. 129-141.

Jiménez, M. y Farias, P. (2002): "New radiometric and geomorphologic evidences of a Last Glacial Maximum older than $18 \mathrm{ka}$ in SW European mountains: the example of Redes Natural Park (Cantabrian Mountains, NW Spain)". Geodinamica Acta, 15, pp. 93-101.

Julivert, M. (1967): "La ventana tectónica del río Color y la prolongación septentrional del Manto del Ponga (Cordillera Cantábrica, España)". Trabajos de Geología, 1, pp. 1-26.

Julivert, M. (1983): "La estructura de la Zona Cantábrica", en J. A. Comba (coord.): Geología de España. Libro jubilar a J. Ma . Ríos. Madrid, IGME, pp. 339-381.

Lewis, C. J., McDonald, E. V., Sancho, C., Peña, J. L. y Rhodes, E. J. (2009): “Climatic implications of correlated Upper Pleistocene glacial and fluvial deposits on the Cinca and Gállego Rivers (NE Spain) based on OSL dating and soil stratigraphy". Global and Planetary Change, 67, pp. 141-152. 
Marquínez, J. (1978): "Estudio geológico del sector SE de los Picos de Europa (Cordillera Cantábrica, NW de España)".Trabajos de Geología, 10, pp. 295-315.

Marquínez, J. (1989): "Mapa geológico de la Región del Cuera y los Picos de Europa". Trabajos de Geología, 18, pp. 137-144.

Mary, G. (1983): "Evolución del margen costero de la Cordillera Cantábrica en Asturias desde el Mioceno". Trabajos de Geología, 13, pp. 3-35.

Moreno, A., Valero-Garcés, B. L., Jiménez-Sánchez, M., Domínguez-Cuesta, M. J., Mata, M. P., Navas, A., González-Sampériz, P., Stoll, H., Farias, P., Morellón, M., Corella, J. P. y Rico, M. (2010): "The last deglaciation in the Picos de Europa National Park (Cantabrian Mountains, Northern Spain)”. Journal of Quaternary Science, doi:10.1002/jqs.1265.

Navarro, D. y Leyva, F. (1986): Mapa Geológico de España. Escala 1:50.000. Hoja de Ribadesella (n. $\left.{ }^{\circ} 31,15-04\right)$. Madrid, IGME, 109 pp. y mapa desplegable.

Navarro, D., Leyva, F. y Villa, E. (1986): "Cambios laterales de facies en el Carbonífero del Oriente de Asturias (Cordillera Cantábrica, Norte de España)". Trabajos de Geología, 16, pp. 87-102.

Noval, M. (1995): "Seguimiento arqueológico de la Autovía Oviedo-Pola de Siero: el yacimiento de Paredes (Siero) 1990-1991". Excavaciones arqueológicas en Asturias 1991-1994. Consejería de Cultura del Principado de Asturias, Oviedo, pp. 253-257.

Reimer, P. J., Baillie, M. G. L., Bard, E., Bayliss, A., Beck, J. W., Bertrand, C. J. H., Blackwell, P. G., Buck, C. E., Burr, G. S., Cutler, K. B., Damon, P. E., Edwards, R. L., Fairbanks, R. G., Friedrich, M., Guilderson, T. P., Hogg, A. G., Hughen, K. A., Kromer, B., McCormac, F. G., Manning, S. W., Ramsey, C. B., Reimer, R. W., Remmele, S., Southon, J. R., Stuiver, M., Talamo, S., Taylor, F. W., Van Der Plicht, J., y Weyhenmeyer, C. E. (2004): "IntCal04 Terrestrial radiocarbon age calibration, 26 - 0 ka BP". Radiocarbon, 46, pp. 1029-1058.

Requejo, O. y Jiménez, M. (2003): "Investigaciones geoarqueológicas en monasterios medievales: el ejemplo de San Pedro de Villanueva (Asturias)", en G. Flor (ed.): Actas de la XI Reunión nacional de Cuaternario. Oviedo, AEQUA, pp. 287-292.

Rodríguez, J. A. (1983): "Excavaciones en el yacimiento de Paredes (Siero, Asturias) y los yacimientos del Paleolítico inferior en la cuenca media de los ríos Nora y Noreña". Noticiario Arqueológico Hispánico, 15, pp. 9-37.

Rodríguez, J. A. (2001): Yacimiento de Cabo Busto. Los orígenes prehistóricos de Asturias. Luarca, G.E.A.

Smart, P. L. (1986): "Origin and development of glacio-karst closed depressions in the Picos de Europa, Spain”. Zeitschrift für Geomorphologie N. F., 30, pp. 423-443.

Ugarte, F. M., González, J. A. y Alonso F. (1984): “Acumulaciones detríticas cuaternarias en el valle del río Oñati (Guipúzcoa)”. Munibe, 36, pp. 65-91.

Ugarte, F. M., López-Azcona, C. y González, J. A. (1986): "Evaluación geomorfológica de los depósitos aluviales de las cuevas de Iritegi y Artzen-Koba (Valle del río aranzazu. Oñati. Guipúzcoa)". Munibe, 38, pp. 15-39. 


\title{
RESUMEN
}

Se analiza el sistema de terrazas fluviales del río Cares y sus tributarios, Casaño y Ribeles, en la depresión de Arenas de Cabrales. En concreto, se han identificado un total de nueve niveles de terraza elevados a +90 m, +60 m, +42-50 m, +20-22 m, +14-17 m, $+12 \mathrm{~m},+8-10 \mathrm{~m},+6-7 \mathrm{~m}$ y $+5 \mathrm{~m}$ sobre el nivel actual del río. También se estudian las características sedimentológicas de los depósitos aluviales y su relación con otras formas de modelado, tales como derrubios estratificados y conos torrenciales; y se aporta una cronología para dos niveles de terraza basada en dataciones absolutas de $\mathrm{C}^{14}$, así como una tasa de incisión del río Cares durante los últimos 37.000 años de $0,24 \mathrm{~mm} / \mathrm{año}$.

Palabras Clave: Terrazas fluviales; dinámica fluvial; sedimentología; dataciones de C14; río Cares; Picos de Europa; Cordillera Cantábrica.

\begin{abstract}
The fluvial terraces of the Cares river: sedimentological and chronological contributions (Picos de Europa, Asturias). An analysis of the system of fluvial terraces in the Cares River and its tributaries in Arenas de Cabrales is presented. A total of nine terrace levels were identified with heights of $+90 \mathrm{~m},+60 \mathrm{~m},+60 \mathrm{~m},+42-50 \mathrm{~m},+20-22 \mathrm{~m},+14-17$ $\mathrm{m},+12 \mathrm{~m},+8-10 \mathrm{~m},+6-7 \mathrm{~m}$ and $+5 \mathrm{~m}$ above the actual river bed. The sedimentological features of alluvial deposits and their relations with others landforms (stratified debris and alluvial cones) have been studied, outlining a chronology for two terrace levels based in absolute datings of ${ }^{14} \mathrm{C}$, as well as an incision rate of Cares river of 0.24 $\mathrm{mm}$ /year during the last 37.000 years.
\end{abstract}

KEY WORDS: Fluvial terraces; fluvial dynamic; sedimentology; ${ }^{14} \mathrm{C}$ datings; Cares river; Picos de Europa; Cantabrian Range.

\section{RÉSUMÉ:}

Les terrasses fluviales de la rivière Cares: des contributions sédimentologiques et chronologiques (aux Pics d'Europe, Asturies). On analyse le système des terrasses fluviales de la rivière Cares et de ses affluents, Casaño et Ribeles, à Arenas de Cabrales (Picos de Europa). En somme, on a identifié un total de 9 niveaux de terrasse situés à +90 m, +60 m, +42-50 m, +20-22 m, +14-17 m, +12 m, +8-10 m, +6-7 m et +5 m sur le niveau actuel de la rivière. On étudie aussi les caractéristiques sédimentologiques des dépôts alluviaux et leur relation avec d'autres formes de modelé comme les éboulis ordonnés et les cônes torrentiels, en ébauchant une chronologie pour deux niveaux de terrasse sur des datations absolues de $\mathrm{C}^{14}$, ainsi qu'un taux d'incision de la rivière Cares pendant les 37.000 dernières années de 0,24 mm/an.

Mots CLÉs: Terrasses fluviales; dynamique fluviale; sédimentologie; datations absolues de C14; rivière Cares; Picos de Europa; Chaîne Cantabrique. 